\title{
Online molecular characterisation of organic aerosols in an atmospheric chamber using extractive electrospray ionisation mass spectrometry
}

\author{
Peter J. Gallimore $^{1}$, Chiara Giorio ${ }^{1, a}$, Brendan M. Mahon ${ }^{1}$, and Markus Kalberer ${ }^{1}$ \\ ${ }^{1}$ Department of Chemistry, University of Cambridge, Lensfield Road, Cambridge, CB2 1EW, UK \\ anow at: Dipartimento di Scienze Chimiche, Università degli Studi di Padova, via Marzolo 1, 1335131 Padua, Italy
}

Correspondence to: Peter J. Gallimore (pjg48@cam.ac.uk) and Markus Kalberer (markus.kalberer@atm.ch.cam.ac.uk)

Received: 13 July 2017 - Discussion started: 19 July 2017

Revised: 18 October 2017 - Accepted: 22 October 2017 - Published: 6 December 2017

\begin{abstract}
The oxidation of biogenic volatile organic compounds (VOCs) represents a substantial source of secondary organic aerosol (SOA) in the atmosphere. In this study, we present online measurements of the molecular constituents formed in the gas and aerosol phases during $\alpha$-pinene oxidation in the Cambridge Atmospheric Simulation Chamber (CASC). We focus on characterising the performance of extractive electrospray ionisation (EESI) mass spectrometry (MS) for particle analysis. A number of new aspects of EESIMS performance are considered here. We show that relative quantification of organic analytes can be achieved in mixed organic-inorganic particles. A comprehensive assignment of mass spectra for $\alpha$-pinene derived SOA in both positive and negative ion modes is obtained using an ultra-high-resolution mass spectrometer. We compare these online spectra to conventional offline ESI-MS spectra and find good agreement in terms of the compounds identified, without the need for complex sample work-up procedures. Under our experimental conditions, EESI-MS signals arise only from particlephase analytes. High-time-resolution (7 min) EESI-MS spectra are compared with simulations from the near-explicit Master Chemical Mechanism (MCM) for a range of reaction conditions. We show that MS peak abundances scale with modelled concentrations for condensable products (pinonic acid, pinic acid, OH-pinonic acid). Relative quantification is achieved throughout SOA formation as the composition, size and mass $\left(5-2400 \mu \mathrm{g} \mathrm{m}^{-3}\right)$ of particles is evolving. This work provides a robust demonstration of the advantages of EESI-MS for chamber studies over offline ESI-MS (time resolution, relative quantification) and over "hard" online techniques (molecular information).
\end{abstract}

\section{Introduction}

Airborne particulate matter has significant impacts on global climate (Hallquist et al., 2009), human health (Dominici et al., 2006) and visibility (Husar et al., 1981). Organic compounds typically comprise around $50 \%$ of submicron aerosol mass (Jimenez et al., 2009). Most of this is secondary and biogenic in origin (Hallquist et al., 2009); the oxidation of biogenic volatile organic compounds (VOCs) such as monoterpenes and isoprene represents a major source of atmospheric secondary organic aerosol (SOA) (Kroll and Seinfeld, 2008; Ziemann and Atkinson, 2012). However, SOA formation processes remain highly uncertain and this is regarded as a major weakness in the current understanding and model representation of atmospheric aerosols (Boucher et al., 2013). The chemistry involved is complex, and the range of organic compounds present in the atmosphere is extremely diverse (Goldstein and Galbally, 2007). Understanding how SOA components form and react is therefore a conceptual and analytical challenge (Noziere et al., 2015).

Identifying and quantifying individual organic components in this complex mixture is commonly achieved using mass spectrometry (MS). A great deal of insight into SOA formation and aging from monoterpenes has been provided by established instruments such as the aerosol mass spectrometer (AMS; Aiken et al., 2008; DeCarlo et al., 2006; Jayne et al., 2000). Of particular utility for understanding organic reaction mechanisms are so-called "soft" ionisation techniques, which retain molecular structure during ion formation (Hoffmann et al., 2011). Most conventional soft ionisation MS is "offline", where chemical analysis is performed 
subsequent to sampling. Techniques such as electrospray ionisation (ESI) MS have been applied widely in atmospheric chemistry and have yielded extensive insight into aerosol chemical processes (e.g. Claeys et al., 2009; Edney et al., 2005; Kampf et al., 2012; Kourtchev et al., 2014). However, there are drawbacks to offline ESI-MS: the time resolution of measurements depends on the frequency at which new aerosol samples are collected, which is typically an hour or more for chamber and ambient sampling. There is also potential for sampling artefacts (Turpin et al., 2000) and a lack of analyte quantification when used in a direct-infusion mode.

A number of recent studies have therefore developed online or semi-continuous atmospheric-pressure ionisation (API) MS techniques (Bateman et al., 2009; Brüggemann et al., 2015; Clark et al., 2014; Nah et al., 2013; Pereira et al., 2014; Vogel et al., 2013; Zhang et al., 2015; Zhao et al., 2017b). In this paper, we focus on the application of one such approach to organic aerosol analysis, namely extractive electrospray ionisation (EESI) MS. The EESI process predominantly forms molecular ions $\left([\mathrm{M}+\mathrm{H}]^{+}\right.$and $\left.[\mathrm{M}-\mathrm{H}]^{-}\right)$and is able to efficiently ionise organic analytes even in complex sample matrices such as urine (Devenport et al., 2014), beer (Zhu et al., 2010) and olive oil (Law et al., 2010). Doezema et al. (2012) demonstrated an initial application of EESI-MS to organic aerosols, identifying a number of products formed from $\alpha$-pinene ozonolysis in positive ion mode. Horan et al. (2012) reported a related technique for particle- and gasphase chemical characterisation, ambient electrospray ionisation (AESI).

Our earlier study reported the first quantification of the EESI aerosol extraction process for carboxylic acid particles (Gallimore and Kalberer, 2013). The detected MS peak abundance scaled in direct proportion with the aerosol mass concentration and was independent of particle diameter in the ranges studied (3-600 $\mu \mathrm{g} \mathrm{m}^{-3}, 70-200 \mathrm{~nm}$ ). Gallimore et al. (2017a) applied the technique for the first time to characterising the kinetics of particle-phase reactions, using the ozonolysis of oleic acid particles as a model system. Changes in relative abundances of ions were used successfully as a proxy for relative concentrations and complex oligomeric species could be detected with minimal molecular fragmentation. Very recently, we demonstrated the ability of the ion source to stably operate for several hours during the evolution of limonene SOA (Gallimore et al., 2017b).

In the current study, we evaluate in detail the use of EESIMS for atmospheric chamber experiments. Large-volume atmospheric chambers have proven to be a valuable means of exploring volatile organic compound (VOC) oxidation mechanisms because a simplified subset of reactions can be investigated under well-defined conditions (Cocker et al., 2001; Gallimore et al., 2017b; Paulsen et al., 2005). We investigate SOA formation from the ozone-initiated oxidation of $\alpha$-pinene, the most abundant monoterpene in the troposphere (with estimated emissions $\sim 60 \mathrm{Tg} \mathrm{yr}^{-1}$; Guenther et al., 2012). $\alpha$-Pinene forms SOA from the condensation of low-volatility oxidised products, and is a major source of biogenic aerosol (Claeys et al., 2009; Jenkin, 2004; Kristensen et al., 2013). Species identified here are compared to previous experimental studies and model representations of the oxidation pathways.

Ultra-high-resolution mass spectra of $\alpha$-pinene SOA are obtained using EESI operating in both ion polarities (+ and -). EESI-MS is used alongside proton transfer reaction (PTR) MS (Blake et al., 2009) to obtain molecular-level gasand particle-phase information with high time resolution. We are particularly interested in the ability of EESI-MS to provide quantitative information such as concentration changes during aerosol formation and aging. We initially confirm that relative quantification of individual organic species is possible in mixed organic-inorganic particles. This is then extended to chemically complex chamber SOA, where the particle composition, size and mass is evolving over time. In particular, we find that EESI(-) MS peak abundances of condensable products of $\alpha$-pinene oxidation (pinonic acid, pinic acid, OH-pinonic acid) map quantitatively onto simulated concentrations from the Master Chemical Mechanism (MCM; Jenkin, 2004). These findings support the continued use of EESI-MS for chamber experiments and prompt further development of the technique to improve sensitivity for other applications.

\section{Methods}

\subsection{Quantification of mixed organic-inorganic particles with EESI}

An aerosol generation system, described in detail by Gallimore and Kalberer (2013), was used to produce model aerosols for quantifying the extraction and ionisation of organic compounds in the presence of inorganic salts (Fig. S1 in the Supplement).

Aerosols were produced from aqueous solutions using a custom-made constant-output atomiser. Solutions containing L-tartaric acid (99\%, Aldrich) and ammonium sulfate $(99.5 \%$, Fluka) in water (HPLC grade, Rathburn) were prepared. The total solute concentration was held constant at $0.1 \mathrm{~mol} \mathrm{~L}^{-1}$. The solute mole fractions (excluding water) were varied and four stock solutions were prepared with the following tartaric acid mole fractions $\left(x_{\mathrm{TA}}\right): 1,0.98,0.9,0.5$, the remainder being composed of ammonium sulfate $\left(x_{\mathrm{AS}}=\right.$ $1-x_{\mathrm{TA}}$ ). The nebuliser was supplied with $\mathrm{N}_{2}$ (oxygen-free nitrogen, BOC) at a pressure of 3 bar to produce an output flow rate of $1.3 \mathrm{~L} \mathrm{~min}^{-1}$. 
A silica diffusion dryer was used to produce dry particles $(<10 \% \mathrm{RH})$. The dried polydisperse particles were size-selected in the range $50-200 \mathrm{~nm}$ prior to EESI-MS analysis using a differential mobility analyser (DMA) (TSI model 3081). The outflow from the DMA was split, with $0.3 \mathrm{~L} \mathrm{~min}^{-1}$ sampled by a condensation particle counter (CPC) (TSI model 3775) to measure the size-selected particle concentration. The remaining $1 \mathrm{~L} \mathrm{~min}^{-1}$ was introduced into the EESI source. Particle mass concentrations were calculated from the CPC number concentration by assuming an aerosol density of $1.78 \mathrm{~g} \mathrm{~cm}^{-3}$, close to the bulk densities of tartaric acid $\left(1.79 \mathrm{~g} \mathrm{~cm}^{-3}\right)$ and ammonium sulfate $\left(1.77 \mathrm{~g} \mathrm{~cm}^{-3}\right)$. A single mode was observed in the particle size distribution for all nebuliser solutions; particles were therefore assumed to be internally mixed with a composition representative of the bulk nebuliser solution. The mass concentrations were corrected for the transmission of multiply charged particles through the DMA according to the method described in Gallimore and Kalberer (2013).

\subsection{Atmospheric chamber operation}

Experiments on the oxidation of biogenic VOCs were performed in the newly commissioned Cambridge Atmospheric Simulation Chamber (CASC), which is characterised in detail in Gallimore et al. (2017b). Aspects of the chamber operation relevant to the results in this paper are described briefly here (see also Fig. S2).

The chamber consists of a $5.4 \mathrm{~m}^{3}$ fluorinated ethylene propylene (FEP) bag housed in an aluminium frame. Gas introduction and sampling are achieved through stainless steel flanges containing Swagelok fittings at the front and rear of the chamber. A series of mass flow controllers (MKS, 5$200 \mathrm{~L} \mathrm{~min}^{-1}$ ) are used to control flows into the chamber. The frame houses opaque perspex screens to block light from entering the chamber during "dark" reactions. The chamber is cleaned between experiments by flushing clean air from a zero air generator (Parker Hannifin KA-MT2) through the chamber using a mass flow controller and pump (Charles Austen ET200) at matched $200 \mathrm{~L} \mathrm{~min}^{-1}$ flows. Ozone and "hard" UV lights may also optionally be used during cleaning.

Aerosol formation was investigated for the dark reaction between $\alpha$-pinene and ozone in the presence of inorganic seed particles. The chamber was filled with clean air from the zero air generator. Water vapour was introduced by bubbling air at $5 \mathrm{~L} \mathrm{~min}^{-1}$ through a heated round-bottomed flask containing water. The chamber's relative humidity $(\mathrm{RH})$ and temperature were monitored using a Honeywell HIH4000 probe and were typically $60 \% \mathrm{RH}$ and $291 \mathrm{~K}$ respectively in these experiments. Seed aerosols were produced from ammonium sulfate solutions using a nebuliser and dryer as described above. The seed particle concentration in the chamber was $\sim 5 \mu \mathrm{g} \mathrm{m}^{-3}$. The $\alpha$-pinene (98\%, Aldrich) was evaporated into the chamber from an impinger using clean air.
Table 1. Conditions used in the chamber experiments in this paper. In all cases, the chamber humidity was adjusted to $60 \% \mathrm{RH}$ and $\sim 5 \mu \mathrm{g} \mathrm{m}^{-3}$ ammonium sulfate seed particles were introduced prior to $\alpha$-pinene and ozone introduction.

\begin{tabular}{lrrl}
\hline Experiment & $\begin{array}{r}{[\alpha \text {-pinene }]_{0}} \\
(\mathrm{ppb})\end{array}$ & $\begin{array}{r}{\left[\mathrm{O}_{3}\right]_{\max }} \\
(\mathrm{ppb})\end{array}$ & $\begin{array}{l}\text { Online MS } \\
\text { sampling }\end{array}$ \\
\hline Low & 45 & 145 & PTR, EESI(-) \\
Medium 1 & 99 & 320 & PTR, EESI $(-)$ \\
Medium 2 & $100^{*}$ & 325 & EESI $(+)$ \\
High & 502 & 1450 & PTR, EESI(-) \\
\hline
\end{tabular}

* Estimated concentration, since PTR-MS was not used in this experiment.

Ozone was produced by flowing air through a photolysis tube containing a mercury UV lamp (Appleton Woods) at $10 \mathrm{~L} \mathrm{~min}^{-1}$, corresponding to a change in the chamber $\left[\mathrm{O}_{3}\right]$ of $\sim 50 \mathrm{ppb} \mathrm{min}^{-1}$. The concentration in the chamber was monitored using a photometric ozone analyser (Thermo Scientific model 49i) and ozone was introduced until $\left[\mathrm{O}_{3}\right] /[\alpha-$ pinene $]_{0} \sim 3$ was achieved $(\sim 3-30 \mathrm{~min})$. The range of $\alpha$ pinene and ozone concentrations used in the chamber are detailed in Table 1.

An air "sprinkler" system, consisting of a $2 \mathrm{~m}$ PTFE tube with a series of small holes along its length, was supplied with high-pressure bursts of air to mix the chamber constituents without recourse to a fan. The air sprinkler leads to the addition of $\sim 100 \mathrm{~L}$ clean air during ozone introduction, and results in a mixing time of a few minutes (Gallimore et al., 2017b). The size distribution of aerosols in the chamber was monitored using an SMPS (TSI model 3936). To enable presentation of data as measured, including "raw" EESI-MS time series, wall-loss correction was not attempted and therefore we focus primarily on the initial time following ozone introduction, where aerosol production will dominate over loss to the chamber walls.

\subsection{EESI source operation and chamber sampling}

The EESI source was described in detail in Gallimore and Kalberer (2013). Briefly, it consists of a custom-built aerosol injector and housing which is interfaced with a commercially available ESI source. The primary solvent electrospray can generate droplets with positive or negative charges depending on the potential difference between the ESI probe and the mass spectrometer. Particle-droplet collisions dissolve the aerosol analytes, which are ionised and ejected into the gas phase by a Coulomb explosion mechanism.

Here the primary solvent was a water-methanol $1: 1$ mixture by volume (Optima LC-grade solvents, Fisher Scientific) containing $0.05 \%$ formic acid ( $90 \%$, Breckland) as a spray modifier. The solvent flow rate was set to $10 \mu \mathrm{L} \mathrm{min}^{-1}$. The nitrogen sheath gas flow rate was set to $0.8 \mathrm{~L} \mathrm{~min}^{-1}$. The potential difference was set to +3.0 and $-3.0 \mathrm{kV}$ for positive and negative ion modes respectively. The aerosol injector de- 


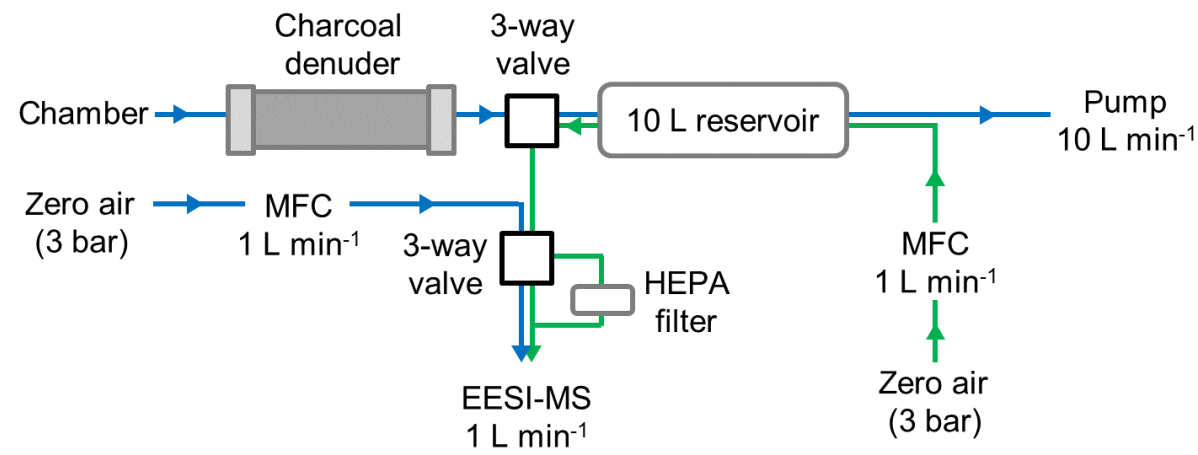

Figure 1. Batch sampling system used to supply the EESI source with chamber air in a two-step process. Blue lines: air is drawn from the chamber into an intermediate $10 \mathrm{~L}$ reservoir, during which time the EESI source is flushed with zero air and a blank spectrum is acquired ( $3.5 \mathrm{~min})$. Green lines: chamber air from the flow tube is pushed through to the EESI source to acquire a sample spectrum (3.5 min).

livers particles into the primary solvent spray at a flow rate of $1 \mathrm{~L} \min ^{-1}$. We refer to these operating conditions as $\operatorname{EESI}(+)$ and $\operatorname{EESI}(-)$ for the remainder of the paper.

The commercial ESI housing was found not to be air tight, so a batch sampling procedure was adopted to introduce particles from the chamber into the EESI source (Fig. 1).

Air was drawn from the chamber at $10 \mathrm{~L} \mathrm{~min}^{-1}$ through a charcoal denuder, used to remove ozone and VOCs, into an intermediate reservoir of approximately $10 \mathrm{~L}$. During this time, the aerosol injector and EESI source were flushed with $1 \mathrm{~L} \mathrm{~min}^{-1}$ synthetic air (zero-grade, BOC) to obtain a "blank" mass spectrum and maintain a constant gas flow into the source (blue flow configuration in Fig. 1). After $3.5 \mathrm{~min}$, the air flush and pump were switched off and threeway valves were used to isolate the reservoir from the chamber and connect it to the EESI source. Air was then pushed through the reservoir and into the source at $1 \mathrm{~L} \mathrm{~min}^{-1}$ and a sample mass spectrum acquired (green flow configuration in Fig. 1). An optional high-efficiency particle air (HEPA) filter (HEPA CAP, Whatman) was used to test the possible contribution of gas-phase species to the observed MS signal.

Repetition of this cycle allowed batch sampling with a time resolution of $7 \mathrm{~min}$. Particle losses using the sampling system in this way were characterised using an SMPS and were $\sim 10 \%$ of the total aerosol mass. Chamber air in the reservoir volume was not expected to be diluted significantly by the $1 \mathrm{~L} \mathrm{~min}^{-1}$ inflow during sample acquisition under the laminar flow conditions used (discussed in the Supplement).

\subsection{SOA filter sampling and analysis}

Filter samples of SOA were collected during the same experiments as the online composition measurements. The sampling and analysis protocol was based on that described in Kourtchev et al. (2014). Briefly, particles were drawn through a charcoal denuder and collected onto cleaned quartz fibre filters (Pallflex ${ }^{\circledR}$ Tissuquartz 2500QAT-UP, 47 mm diameter) $1 \mathrm{~h}$ after the introduction of ozone to the chamber. Chamber air was collected for $30 \mathrm{~min}$ at $15 \mathrm{~L} \mathrm{~min}^{-1}$, resulting in a total volume collected of $450 \mathrm{~L}$. One-quarter of the filter was extracted in $2 \mathrm{~mL}$ of methanol (LC-MS grade, Fisher Scientific) using a vortex mixer; $2 \mathrm{~mL}$ of water (LC-MS grade, Fisher Scientific) and $0.1 \%$ by volume formic acid was added to the extract, which was analysed by direct infusion nanoESI (Advion Triversa Nanomate) MS with a back pressure of $0.8 \mathrm{psi}$ and an ionisation potential difference of $-1.4 \mathrm{kV}$.

\subsection{Ultra-high-resolution MS operation and data analysis}

The EESI and nanoESI sources were coupled to an ultrahigh-resolution mass spectrometer (Thermo Scientific LTQ Orbitrap Velos). Mass spectra were acquired in the range $m / z \quad 100-500$ with mass accuracy $<1.5 \mathrm{ppm}$ and resolution of 100000 (full width at half maximum, FWHM) at $m / z 400$. These characteristics mean that unambiguous molecular formula assignments for reaction product ions can be routinely achieved.

Mass spectra generated from EESI and offline nanoESI samples were analysed using a method similar to that described in Zielinski et al. (2017). Briefly, possible formulae were assigned to the spectra using XCalibur 2.1 software (Thermo Scientific). Evaluation of these initial assignments was performed using an in-house code run in Mathematica 10 (Wolfram Research Inc.). This removes formulae which fall outside a 2 ppm mass tolerance and those deemed implausible based on their atomic ratios. By strictly limiting permitted elements, we reduce the number of erroneous permutations of formulae that coincide with the measured $\mathrm{m} / \mathrm{z}$. Based on the oxygenated VOCs expected for $\alpha$-pinene SOA (Table 2), we retained assignments containing only carbon, hydrogen and oxygen, and permitted sodium adduct formation in positive ion mode. Nitrogen-containing compounds are not expected to form via ozonolysis, but we note that this treatment excludes possible $\left[\mathrm{M}+\mathrm{NH}_{4}\right]^{+}$adducts derived from the ammonium sulfate seed particles. However, in the raw data, such clusters were not apparent for major positive mode species such as pinonaldehyde. Following 
this assignment, the blank spectrum was subtracted and lowabundance peaks deemed to fall below the noise of the Orbitrap instrument were removed to yield the final spectra.

Time series of individual particle-phase ions were also extracted from Xcalibur. These raw time series were processed by removing the transitions between sample and blank periods $(\sim 0.5 \mathrm{~min})$, averaging the abundance of the remaining sample period, and subtracting the averaged blank abundance for the minute preceding each sample. The resulting data points, with 7 min time resolution, were shifted in time to account for the delay between sampling from the chamber and detection by EESI-MS. Uncertainties on the MS abundances represent the combined standard deviation of the sample and blank signals.

\subsection{PTR-MS operation and data analysis}

Gas-phase VOC concentrations were measured using a PTR mass spectrometer (PTR-ToF-MS 8000, Ionicon Analytik, Innsbruck, Austria) in the range $m / z, 10-500$ and with a time resolution of $10 \mathrm{~s}$. Parameters of the PTR-MS during the experiments were as follows: drift tube voltage: $600 \mathrm{~V}$, drift tube pressure $\approx 2.20 \mathrm{mbar}$, drift tube temperature: $60^{\circ} \mathrm{C}$, resulting in a field density ratio $\mathrm{E} / \mathrm{N}$ of ca. $135 \mathrm{Td}\left(1 \mathrm{Td}=10^{-17} \mathrm{~V} \mathrm{~cm}^{2}\right)$. Resolution in the time-offlight (ToF) detector was 5000 (FWHM) at the mass of protonated acetone during all experiments. The MS inlet (PEEK tube, $60^{\circ} \mathrm{C}$, flow rate $0.1 \mathrm{~L} \mathrm{~min}^{-1}$ ) was connected to the chamber with a $1 \mathrm{~mm}$ inner diameter PTFE tube at room temperature.

Data analysis for the PTR-MS was carried out using PTRMS Viewer 3.2 (Ionicon Analytik). Mass calibration was adjusted using $\mathrm{H}_{3}^{18} \mathrm{O}^{+}(m / z=21.023), \mathrm{NO}^{+}(m / z=29.998)$ and $\mathrm{C}_{3} \mathrm{H}_{7} \mathrm{O}^{+}(m / z=59.049)$ as references. For all the compounds, concentrations were estimated on the basis of the rate constant $(k)$ of the proton transfer reaction (Lindinger et al., 1998). Because the PTR rate constants are not known for all compounds, a default rate constant of $2 \times 10^{-9} \mathrm{~cm}^{3}$ molecule ${ }^{-1} \mathrm{~s}^{-1}$ was used for those compounds without a measured rate constant. Exothermic PTRs occur at a rate close to the collision limit (Blake et al., 2009) and known rate constants for a variety of VOCs are within $50 \%$ of this value (Smith and Spanel, 2005).

\subsection{Numerical modelling of chamber chemistry}

The complete reaction scheme for the degradation of $\alpha$ pinene was extracted from the MCM v3.3.1 (Jenkin et al., 1997; Saunders et al., 2003) via the MCM website (http: $/ /$ mcm.leeds.ac.uk/MCM) and used to simulate the ozoneinitiated oxidation of $\alpha$-pinene in the chamber. The reaction scheme was modified to approximate the introduction of ozone over the initial minutes of our experiments - an ozone precursor was added to the mechanism and converted to ozone on the appropriate timescale $(3-30 \mathrm{~min})$. The initial precursor concentrations were selected to reproduce $\left[\mathrm{O}_{3}\right]_{\max }$ from Table 1. See the Supplement for more details about the chemical mechanism used.

Simulations were performed using the box model AtChem (https://atchem.leeds.ac.uk) via a web interface, which enables the use of MCM mechanisms and relevant input parameters from the chamber. AtChem uses the Fortran CVODE library to integrate the MCM reaction scheme ODEs forward in time from the initial input conditions.

AtChem simulates gas-phase chemistry, but not aerosol formation. To compare gas-phase concentrations from the simulation with EESI-MS aerosol measurements, we neglected possible in-particle chemistry and focused on major aerosol components from previous studies referenced in Table 2. Gas-particle partitioning considerations are discussed in Sect. 3.3.2. The AtChem output concentrations (molecules $\mathrm{cm}^{-3}$ ) were converted to parts per billion by volume (ppb) for comparison to PTR-MS measurements and $\mu \mathrm{g} \mathrm{m}^{-3}$ for aerosol species.

\section{Results}

\subsection{Relative quantification of organic analytes in mixed organic-inorganic particles}

EESI-MS approaches have demonstrated excellent tolerance to very complex sample matrices compared to direct ESI-MS (Chen et al., 2006). Here we investigate the possible impact of inorganic salts on the EESI-MS peak abundance of organic ions in mixed aerosol particles. Specifically, we establish the potential impact of inorganic seed particles on the relative quantification of organic acids (detected as $[\mathrm{M}-\mathrm{H}]^{-}$) in the chamber experiments which follow. Measurements quantifying the response of the technique to particles containing known mixtures of tartaric acid (TA) and ammonium sulfate (AS) are given in Fig. 2. TA is a highly oxygenated compound, which is a relevant proxy for species present in aged organic aerosols. Its high water solubility and negligible volatility allow mixed TA-AS particles with precisely known composition to be prepared from solution. Tartaric acid was detected as an $[\mathrm{M}-\mathrm{H}]^{-}$ion in negative ion mode at $m / z$ 149.0092. The abundance of this ion is plotted as a function of tartaric acid aerosol mass concentration, calculated from the total aerosol mass concentration and the tartaric acid mass fraction, in Fig. 2.

As for the single-component aerosol in Gallimore and Kalberer (2013), the detected mass spectrum signal abundance scales linearly with the organic aerosol mass concentration, this time over a range of organic/inorganic aerosol fractions. The best-fit curve for the entire data set in Fig. 2 follows a power law with an exponent of 0.97 , close to the value of 1 expected for such a linear relationship.

The data in Fig. 2 are colour-coded according to the mole fraction of tartaric acid present, $x_{\mathrm{TA}}$. To a good approxima- 


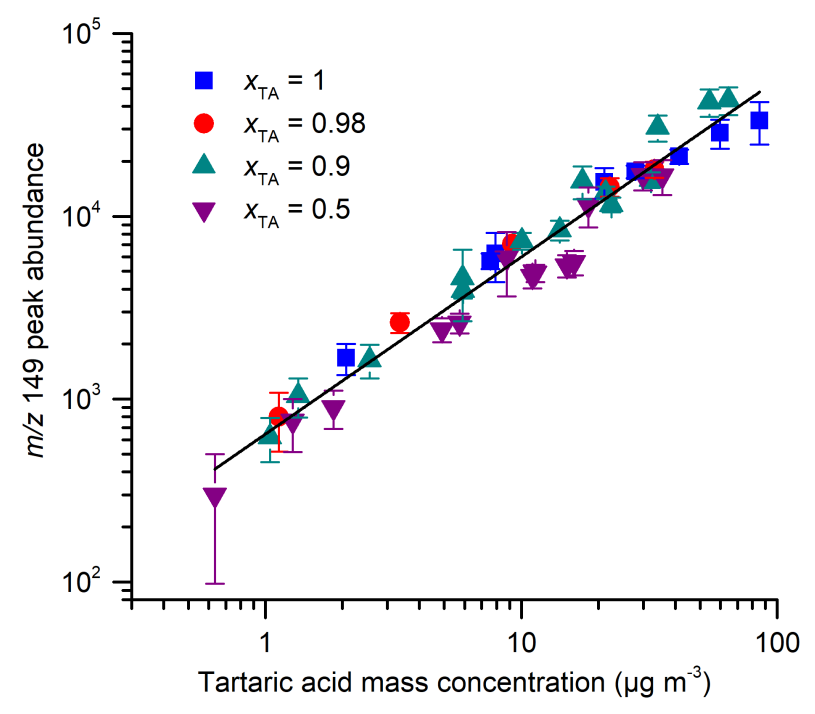

Figure 2. Peak abundance of $m / z 149.0092$ in negative ion mode, assigned to deprotonated tartaric acid, as a function of tartaric acid mass concentration in the aerosol. Particles were produced by nebulising bulk solutions containing varying proportions of tartaric acid and ammonium sulfate. The mole fraction of tartaric acid was varied between 0.5 and 1. Error bars represent the standard deviation of the MS signal over the $1 \mathrm{~min}$ averaging time.

tion, the data for different $x_{\mathrm{TA}}$, and hence different $x_{\mathrm{AS}}$, cluster around a common best-fit curve, suggesting that the different mass fractions of ammonium sulfate do not influence the ionisation efficiency (IE) of tartaric acid. There is limited evidence that higher concentrations of ammonium sulfate may suppress the organic signal; the data with $x_{\mathrm{TA}}=$ $x_{\mathrm{AS}}=0.5$ often fall slightly below the best-fit curve. Figure $\mathrm{S} 3$ suggests that this suppression may result in a signal up to $25 \%$ lower than expected at the highest ammonium sulfate concentrations used.

This is not problematic for the current application because the conditions used in the chamber experiments when EESIMS measurements were made involved low ammonium sulfate concentrations $\left(\sim 5 \mu \mathrm{g} \mathrm{m}^{-3}\right)$ and high organic mole fractions $\left(x_{\text {org }}>0.7\right)$. Although care may be required if using substantially higher salt concentrations (or higher $x_{\text {salt }}$ ) in future studies, the potential suppression effect seems rather limited over the range tested. In this study, we further investigate the relative quantification of individual organic species during the growth of $\alpha$-pinene SOA on ammonium sulfate seeds in Sect. 3.3.2.

\subsection{Molecular characterisation of $\alpha$-pinene oxidation products}

\subsubsection{Assignment and comparison of EESI-MS and PTR-MS spectra}

EESI-MS (particle phase) and PTR-MS (gas phase) were deployed during dark $\alpha$-pinene ozonolysis experiments in the CASC chamber. Our EESI source was operated in both positive $(+)$ and negative $(-)$ ionisation modes for the first time, which can help to identify complementary compound classes. A summary of the most abundant species identified during the "medium" concentration experiments (100 ppb $\alpha$ pinene) is presented in Table 2. Full mass spectra are also shown in Fig. S4 for reference. The low mass thresholds of the EESI-MS and PTR-MS mass analysers were $\mathrm{m} / z 100$ and 10 respectively in this study. In total, $\sim 400$ ions were detected via PTR-MS including product parent ions, fragments and contaminants; > 1000 ions were detected in both EESIMS polarities, with 95 assignments retained in $\operatorname{EESI}(+)$, and 87 in $\operatorname{EESI}(-)$, following data treatment.

The major products identified by EESI-MS and PTR-MS following data treatment compare well to previous literature. Assigning PTR-MS spectra is slightly complicated by fragmentation; abundant products such as pinonaldehyde appear mostly as fragment ions (Wisthaler et al., 2001). Since fragmentation patterns for most VOCs are not known, we have not assigned ions $<m / z, 100$ aside from known major species reported in Blake et al. (2009). However, we present all detected PTR-MS ions in Fig. S4.

A positive characteristic of EESI-MS is that most species are detected as intact quasi-molecular ions (Table 2). Furthermore, the two ion polarities allow detection of complementary compound classes. $\mathrm{EESI}(+)$ mostly forms $\mathrm{H}^{+}$and $\mathrm{Na}^{+}$ clusters with the parent molecule and enables a wide range of functional groups (carbonyls, alcohols, carboxylic acids) to be detected (Table 2). Doezema et al. (2012) reported that $\left[\mathrm{M}-\mathrm{H}_{2} \mathrm{O}+\mathrm{H}\right]^{+}$fragment ions of major products such as pinonic acid and pinonaldehyde were more abundant than corresponding $[\mathrm{M}+\mathrm{H}]^{+}$peaks. We found that such fragments were minor compared to quasi-molecular ions, and not observed for many species. This suggests that the choice of EESI parameters may be an important determinant of fragmentation. Negative ionisation is a more specific technique, which mostly deprotonates acidic functional groups and so carboxylic acids (including multifunctional species) are readily detected as $[\mathrm{M}-\mathrm{H}]^{-}$ions.

Taken together, EESI(-)-MS, EESI(+)-MS and PTR-MS enable the detection of a wide range of typical SOA components and gas-phase oxidation products with different volatilities and polarities. We illustrate this using the twodimensional formulation introduced by Kroll et al. (2011). This calculates a compound's average carbon oxidation state, $\overline{\mathrm{OS}_{\mathrm{c}}}$, as a metric for its degree of oxidation. For molecules 
Table 2. Tentative assignments of a selection of major ions detected by PTR-MS and EESI-MS during dark $\alpha$-pinene ozonolysis experiments with $100 \mathrm{ppb} \alpha$-pinene precursor.

\begin{tabular}{|c|c|c|c|c|}
\hline Neutral mass (Da) & Formula & Possible assignment & PTR-MS ions & EESI-MS ions \\
\hline 136.1252 & $\mathrm{C}_{10} \mathrm{H}_{16}$ & $\alpha$-Pinene ${ }^{\mathrm{a}, \mathrm{b}}$ & $\begin{array}{l}{[\mathrm{M}+\mathrm{H}]^{+}} \\
{\left[\mathrm{C}_{6} \mathrm{H}_{8}+\mathrm{H}\right]^{+}}\end{array}$ & ND \\
\hline 140.0837 & $\mathrm{C}_{8} \mathrm{H}_{12} \mathrm{O}_{2}$ & $\begin{array}{l}\text { 2,2-Dimethyl-cyclobutyl- } \\
\text { 1,3diethanal }{ }^{\mathrm{c}}\end{array}$ & {$[\mathrm{M}+\mathrm{H}]^{+}$} & {$[\mathrm{M}+\mathrm{H}]^{+} ;[\mathrm{M}+\mathrm{Na}]^{+} ;[\mathrm{M}-\mathrm{H}]^{-}$} \\
\hline 140.1201 & $\mathrm{C}_{9} \mathrm{H}_{16} \mathrm{O}$ & $\begin{array}{l}\text { 1-Acetyl-2,2,3- } \\
\text { trimethylcyclobutane }^{\mathrm{c}}\end{array}$ & {$[\mathrm{M}+\mathrm{H}]^{+}$} & {$[\mathrm{M}+\mathrm{H}]^{+} ;[\mathrm{M}-\mathrm{H}]^{-}$} \\
\hline 154.0994 & $\mathrm{C}_{9} \mathrm{H}_{14} \mathrm{O}_{2}$ & Norpinaldehyde $\mathrm{e}^{\mathrm{c}, \mathrm{f}}$ & {$[\mathrm{M}+\mathrm{H}]^{+}$} & {$[\mathrm{M}+\mathrm{H}]^{+} ;[\mathrm{M}+\mathrm{Na}]^{+} ;[\mathrm{M}-\mathrm{H}]^{-}$} \\
\hline 158.0943 & $\mathrm{C}_{8} \mathrm{H}_{14} \mathrm{O}_{3}$ & $\begin{array}{l}\text { 2,2-Dimethyl-3-formyl- } \\
\text { acyclobutylmethanoic acid }\end{array}$ & ND & {$[\mathrm{M}+\mathrm{Na}]^{+} ;[\mathrm{M}-\mathrm{H}]^{-}$} \\
\hline 168.1150 & $\mathrm{C}_{10} \mathrm{H}_{16} \mathrm{O}_{2}$ & Pinonaldehyde $\mathrm{e}^{\mathrm{a}, \mathrm{b}, \mathrm{c}, \mathrm{e}, \mathrm{f}}$ & $\begin{array}{l}{[\mathrm{M}+\mathrm{H}]^{+}} \\
{\left[\mathrm{M}-\mathrm{H}_{2} \mathrm{O}+\mathrm{H}\right]^{+}} \\
{\left[\mathrm{C}_{8} \mathrm{H}_{10}+\mathrm{H}\right]^{+}}\end{array}$ & $\begin{array}{l}{[\mathrm{M}+\mathrm{H}]^{+} ;[\mathrm{M}+\mathrm{Na}]^{+}} \\
{\left[\mathrm{M}-\mathrm{H}_{2} \mathrm{O}+\mathrm{H}\right]^{+}}\end{array}$ \\
\hline 170.0943 & $\mathrm{C}_{9} \mathrm{H}_{14} \mathrm{O}_{3}$ & Pinalic-3-acid ${ }^{e, f}$ & {$[\mathrm{M}+\mathrm{H}]^{+}$} & {$[\mathrm{M}+\mathrm{Na}]^{+} ;[\mathrm{M}-\mathrm{H}]^{-}$} \\
\hline 172.0743 & $\mathrm{C}_{8} \mathrm{H}_{12} \mathrm{O}_{4}$ & Terpenylic acid ${ }^{\mathrm{c}, \mathrm{d}, \mathrm{g}}$ & {$[\mathrm{M}+\mathrm{H}]^{+}$} & {$[\mathrm{M}+\mathrm{H}]^{+} ;[\mathrm{M}+\mathrm{Na}]^{+} ;[\mathrm{M}-\mathrm{H}]^{-}$} \\
\hline 182.0943 & $\mathrm{C}_{10} \mathrm{H}_{14} \mathrm{O}_{3}$ & Oxopinonaldehyde ${ }^{c}$ & {$[\mathrm{M}+\mathrm{H}]^{+}$} & {$[\mathrm{M}+\mathrm{H}]^{+} ;[\mathrm{M}+\mathrm{Na}]^{+} ;[\mathrm{M}-\mathrm{H}]^{-}$} \\
\hline 184.1099 & $\mathrm{C}_{10} \mathrm{H}_{16} \mathrm{O}_{3}$ & Pinonic acid ${ }^{\mathrm{c}, \mathrm{d}, \mathrm{e}, \mathrm{f}}$ & {$[\mathrm{M}+\mathrm{H}]^{+}$} & {$[\mathrm{M}+\mathrm{H}]^{+} ;[\mathrm{M}+\mathrm{Na}]^{+}[\mathrm{M}-\mathrm{H}]^{-}$} \\
\hline 186.0892 & $\mathrm{C}_{9} \mathrm{H}_{14} \mathrm{O}_{4}$ & Pinic acid ${ }^{c, d, e, f}$ & {$[\mathrm{M}+\mathrm{H}]^{+}$} & {$[\mathrm{M}+\mathrm{H}]^{+} ;[\mathrm{M}+\mathrm{Na}]^{+}[\mathrm{M}-\mathrm{H}]^{-}$} \\
\hline 188.0685 & $\mathrm{C}_{8} \mathrm{H}_{12} \mathrm{O}_{5}$ & 2-Hydroxyterpenylic acid ${ }^{c, g}$ & ND & {$[\mathrm{M}-\mathrm{H}]^{-}$} \\
\hline 200.1049 & $\mathrm{C}_{10} \mathrm{H}_{16} \mathrm{O}_{4}$ & OH-pinonic acid ${ }^{\mathrm{c}, \mathrm{d}, \mathrm{e}, \mathrm{f}}$ & {$[\mathrm{M}+\mathrm{H}]^{+}$} & {$[\mathrm{M}+\mathrm{Na}]^{+} ;[\mathrm{M}-\mathrm{H}]^{-}$} \\
\hline 232.0947 & $\mathrm{C}_{10} \mathrm{H}_{16} \mathrm{O}_{6}$ & Diaterpenylic acid acetate $\mathrm{c}, \mathrm{d}, \mathrm{g}$ & ND & {$[\mathrm{M}+\mathrm{Na}]^{+} ;[\mathrm{M}-\mathrm{H}]^{-}$} \\
\hline 358.1628 & $\mathrm{C}_{17} \mathrm{H}_{26} \mathrm{O}_{8}$ & Pinyl-diterpenylic ester ${ }^{\mathrm{d}}$ & ND & {$[\mathrm{M}-\mathrm{H}]^{-}$} \\
\hline
\end{tabular}

Compounds assigned in other studies were used to provide possible assignments here: ${ }^{\mathrm{a}}$ Wisthaler et al. (2001), ${ }^{\mathrm{b}}$ Lee et al. (2006), ${ }^{\mathrm{c}}$ Hall IV and Johnston (2012),

${ }_{\mathrm{d}}$ Kristensen et al. (2013), ${ }^{\mathrm{e}}$ Jenkin (2004), ${ }^{\mathrm{f}}$ Camredon et al. (2010), ${ }^{\mathrm{g}}$ Claeys et al. (2009). ND: not detected.

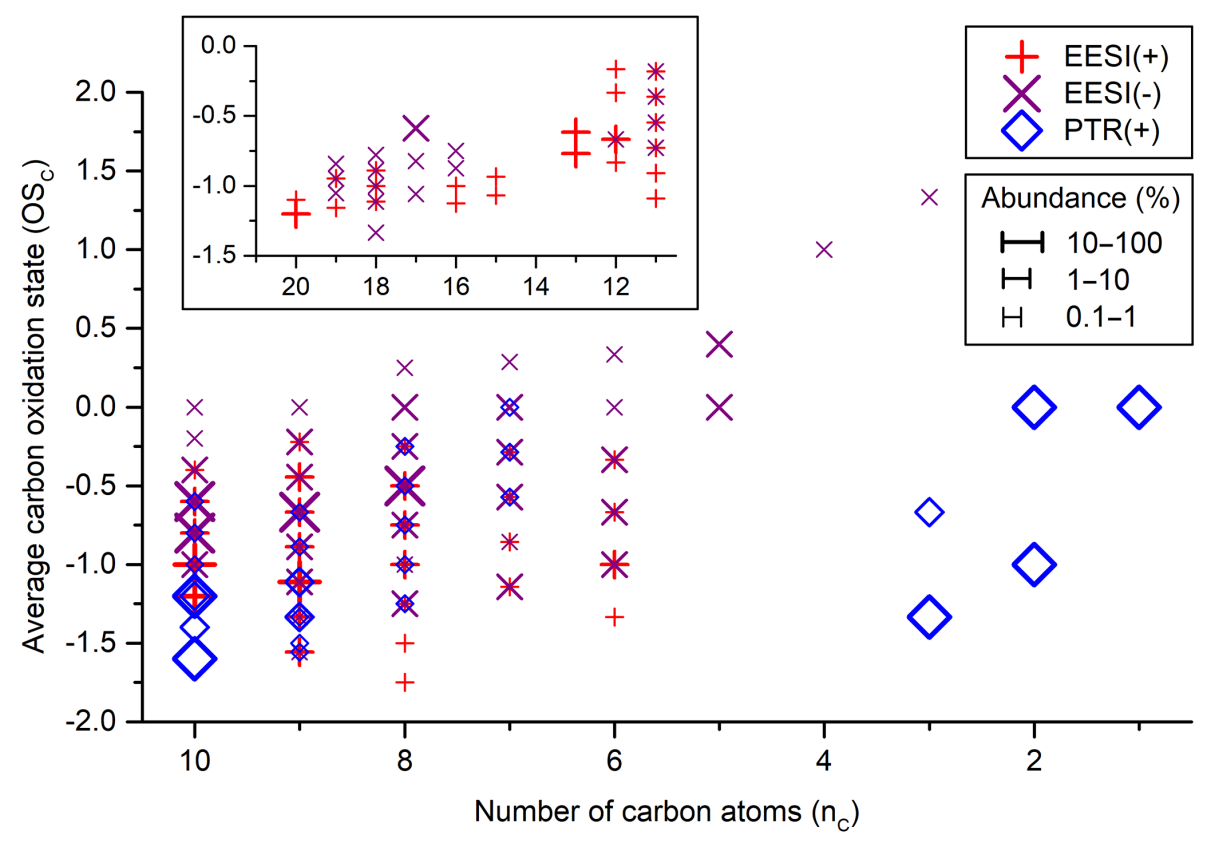

Figure 3. The average carbon oxidation state of compounds detected via EESI-MS and PTR-MS as a function of $n_{\mathrm{C}}$. Spectra were acquired $\sim 1 \mathrm{~h}$ after the start of ozone introduction for the "medium" concentration experiments. Marker size is related to MS abundance according to the size bins indicated in the figure. The inset plot shows oligomeric species $\left(n_{\mathrm{C}}>10\right)$. No PTR-MS signals with $n_{\mathrm{C}}>10$ were detected.

containing only carbon, hydrogen and oxygen:

$\overline{\mathrm{OS}_{\mathrm{c}}}=\frac{2 n_{\mathrm{O}}}{n_{\mathrm{C}}}-\frac{n_{\mathrm{H}}}{n_{\mathrm{C}}}$, where $n_{\mathrm{O}}, n_{\mathrm{C}}$ and $n_{\mathrm{H}}$ are the number of oxygen, carbon and hydrogen atoms respectively. This expression is exact un- 
less oxygen is present in peroxide or other functional groups with oxidation state $\neq 2$. Figure 3 shows calculated $\overline{\mathrm{OS}_{\mathrm{c}}}$ from $\mathrm{PTR}, \operatorname{EESI}(+)$ and $\operatorname{EESI}(-)$ MS assignments as a function of $n_{\mathrm{C}}$. Many PTR-MS ions from Fig. S4 are not assigned to formulae and therefore are not included in Fig. 3.

The ensemble average $\overline{\mathrm{OS}_{\mathrm{c}}}$ for particle-phase products resulting from monoterpene ozonolysis is quoted as -1.1 to -0.5 in Kroll et al. (2011) based on ESI-MS and AMS literature, in good agreement with our $\operatorname{EESI}(+) /(-)-\mathrm{MS}$ observations. Within this ensemble average, however, the ions detected in the two ion polarities, and in the gas phase via PTR-MS, occupy different regions of the $\overline{\mathrm{OS}}-n_{\mathrm{C}}$ space in Fig. 3.

Aside from $\alpha$-pinene, the products detected by PTR-MS with molecular formula assignments mainly fall into two categories: $n_{\mathrm{C}}=1-3$ species resulting from reactions which fragment the $\alpha$-pinene carbon backbone, and $n_{\mathrm{C}}=8-10$ species such as pinonaldehyde resulting from functionalisation reactions. These larger species are sufficiently volatile that a fraction remains in the gas phase, which is reflected in their low average oxidation states $\left(\overline{\mathrm{OS}_{\mathrm{c}}}<-0.5\right)$. However, many are condensable and therefore also detected in the particle phase via EESI $(+)$, which is generally more sensitive to compounds with only carbonyl groups compared to $\operatorname{EESI}(-)$. $\operatorname{EESI}(+)$ ions mostly occupy a region with $-1.5<\overline{\mathrm{OS}_{\mathrm{c}}}<-0.5$, with the most abundant ions assigned as semi-volatile carbonyls such as pinonaldehyde. Carboxylic acids and other functional groups are also present. In addition to functionalisation products, oligomers from accretion reactions, and products resulting from radical-induced carbon backbone fragmentation, can also be detected.

Compounds detected via EESI(-)-MS were on average more oxidised than EESI(+)-MS and PTR-MS and also possess a slightly higher average molecular weight (Fig. S4). The negative ion mode is highly efficient at ionising carboxylic acid functional groups, and these heavier and more oxygenated species tend to condense most readily into the particle phase. A number of low- $n_{\mathrm{C}}$ species and oligomers were also detected, again indicating that multiple generations of chemistry, including secondary $\mathrm{OH}$-mediated fragmentation, was being assessed. We quantitatively compare EESI(-)-MS time series for three of the main condensable oxidation products (pinonic acid, pinic acid and $\mathrm{OH}$-pinonic acid) with model simulations in Sect. 3.3.2.

\subsubsection{Comparison of online EESI(-) and offline nanoESI(-) mass spectra}

Figure 4 shows a comparison in the same $\overline{\mathrm{OS}_{\mathrm{c}}}-n_{\mathrm{C}}$ space as Fig. 3 between online measurements of particle composition via EESI(-)-MS and offline nanoESI(-)-MS analysis following the collection of SOA particles on to quartz fibre filters.

There is good agreement between the two data sets in Fig. 4 in terms of the range of $\overline{\mathrm{OS}_{\mathrm{c}}}$ and $n_{\mathrm{C}}$ detected, and

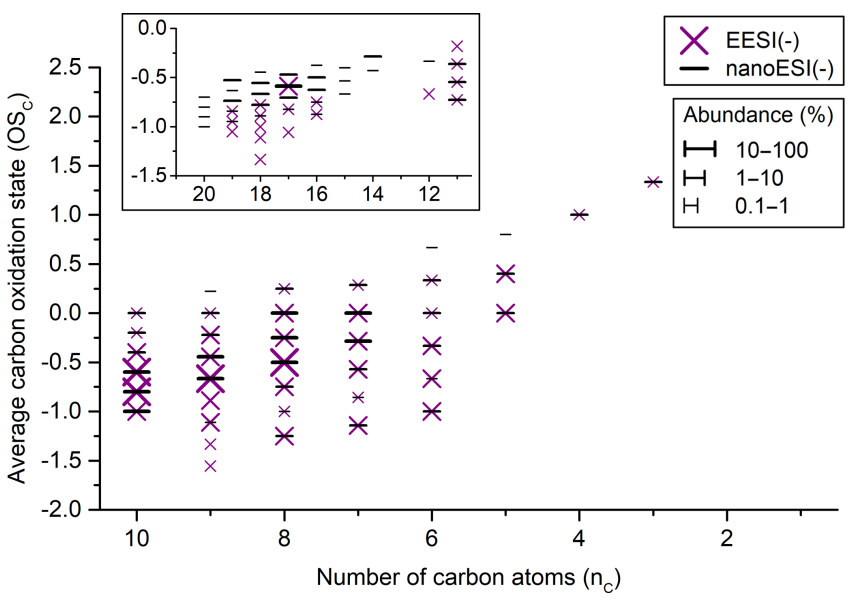

Figure 4. A comparison of $\alpha$-pinene SOA oxidation products detected using online $\operatorname{EESI}(-)$ and offline nanoESI $(-)$ MS. The EESI(-)-MS spectrum acquisition and offline sampling period started $\sim 1 \mathrm{~h}$ after the start of ozone introduction, for the "medium" concentration experiments. Marker size is related to the MS abundance according to the size bins indicated in the figure. The inset plot shows oligomeric species $\left(n_{\mathrm{C}}>10\right)$.

the relative abundances of species in the main plot (indicated by marker size). Pinic acid $\left(n_{\mathrm{C}}=9, \overline{\mathrm{OS}_{\mathrm{c}}}=-0.67\right)$ is the most abundant ion in $\operatorname{EESI}(-)$ and nanoESI $(-)$, and essentially all monomeric compounds present with $\overline{\mathrm{OS}_{\mathrm{c}}}<0$ are detected using both methodologies. A direct comparison of the mass spectra is provided in Fig. 5. The major dimers reported in previous studies (Hall IV and Johnston, 2012; Kristensen et al., 2013; Reinhardt et al., 2007) are also detected using both approaches here. Differences between EESI(-) and nanoESI(-) can be observed in two regions: firstly, a few oxidised monomers with $\overline{\mathrm{OS}_{\mathrm{c}}}>0$ are detected only using the filter method. Secondly, the oligomers detected via nanoESI(-)-MS are more numerous, and generally more oxidised, than for $\operatorname{EESI}(-)$-MS.

The peaks absent from EESI(-)-MS are generally the least abundant in the offline sampling method (Fig. 5), so we suspect differences are mainly a consequence of sample preconcentration and hence improved sensitivity using the filter sampling method. While the EESI source operates at an aerosol flow rate of $\sim 1 \mathrm{~L} \mathrm{~min}^{-1}, 450 \mathrm{~L}$ of chamber air is drawn through the filter for an offline sample. The capture efficiency of aerosols in the EESI process is also expected to be less efficient than extraction from a substrate. An alternative possibility is that offline collection and analysis introduces positive artefacts to the nanoESI(-)-MS spectrum, such as via additional reaction on the substrate. Horan et al. (2012) found that the relative abundance of oligomers was also higher in filter samples than their online AESI method, which was attributed to a negative filter sampling artefact - the evaporation of semi-volatile material (predominantly monomers) during collection. However, the overall 


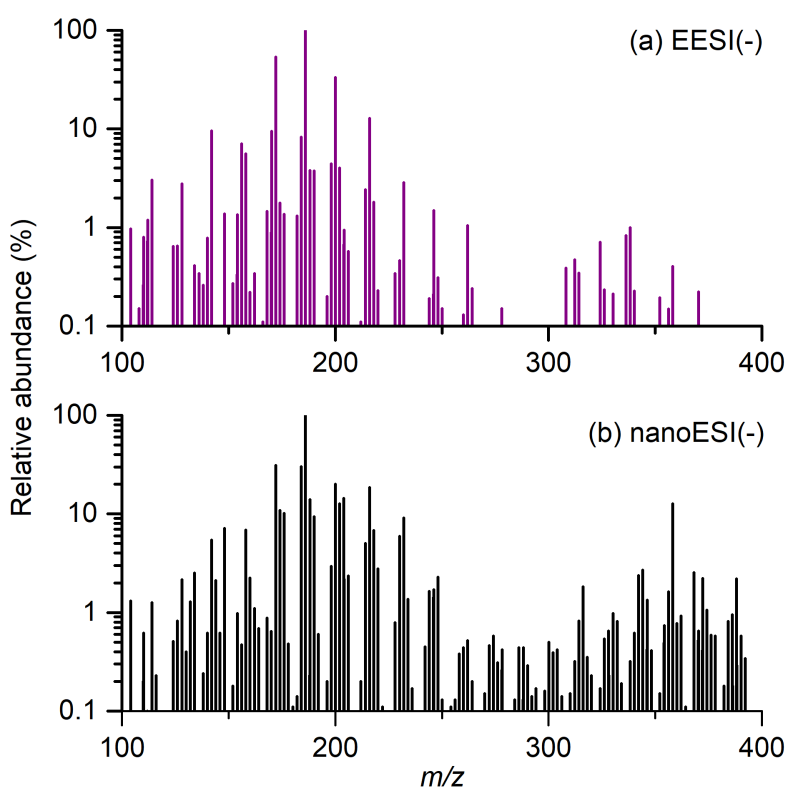

Figure 5. Mass spectra obtained during the dark ozonolysis of $\alpha$ pinene under "medium" conditions (Table 1) using (a) online EESIMS in negative ionisation mode and (b) nanoESI-MS of SOA filter extracts. The online MS was acquired and the filter collected $1 \mathrm{~h}$ after the start of ozonolysis in the chamber. The spectra are very similar in the monomer region $(<250 \mathrm{Da})$, but the oligomers detected are more numerous and possess slightly higher molecular weights in the nanoESI $(-)$ spectrum.

good agreement between the methods is encouraging and the use of both during the same experiment could provide the benefits of offline sampling (sensitivity) and online sampling (time resolution, relative quantification) together.

\subsection{Temporal evolution of molecular composition during $\alpha$-pinene oxidation}

\subsubsection{Time series of individual particle-phase ions}

We now focus on the ability of our online MS techniques to monitor relative concentration changes of individual species during $\alpha$-pinene oxidation. In particular, we monitor some of the major low-volatility products in the particle phase using EESI(-)-MS. Figure 6 shows an illustrative raw time series from the "medium" experimental conditions for $m / z$ 185.0819, assigned to $[\mathrm{M}-\mathrm{H}]^{-}$for an abundant oxidation product, pinic acid (Table 2). We present the MS data in terms of ion abundances with alternating blank and sample measurements. The pinic acid abundance increases over the first hour of the experiment, as does the total aerosol mass (secondary $y$ axis in Fig. 6). Both signals tend towards a plateau at later times. Ions assigned to oxidation products in Table 2 show similar increases over time, although the precise time dependence varies depending on the product.
We show blank-subtracted time series for other aerosol-phase products in the next section.

As configured, the sampling setup enables a blank and chamber measurement to be obtained in a 7 min cycle, a substantially higher time resolution than most other semicontinuous sampling methods (Bateman et al., 2009; Pereira et al., 2014) or collection onto filters. It is comparable to the recent highly time-resolved particle-into-liquid-sampling measurements of Zhang et al. (2015). The signal abundances vary by less than $15 \%$ across a sample window $(3.5 \mathrm{~min})$ (Fig. 6), with most of the decrease attributed to particle deposition in the intermediate reservoir volume and sampling lines. An advantage of flushing the EESI source during each blank period is that baseline changes can be monitored and accounted for. The signals in Fig. 6 rapidly return towards the baseline recorded at the start of the experiment as the source is flushed. Small increases in this baseline (e.g. due to particle deposition in the source) are subtracted during data processing. Importantly, we avoid the major EESI source contamination problems reported in other applications (McCullough et al., 2011). We suspect that this is due to a combination of using relatively low analyte concentrations, the optimised source parameters from Gallimore and Kalberer (2013) and this regular flushing procedure.

The semi-volatile nature of SOA means that both gas- and particle-phase species will be present in the chamber. We examined whether gas-phase species contribute to our observed EESI(-)-MS signal under the "medium" reaction conditions by removing particles from the sample flow using a HEPA filter (Fig. 1). With particles filtered out, none of the species listed in Table 2 could be detected above levels observed for the solvent blanks. This was also the case even if the charcoal denuder in Fig. 1, intended to remove gas-phase species, was bypassed.

The aerosol mass loading in the chamber $\left(\sim 300 \mu \mathrm{g} \mathrm{m}^{-3}\right)$ would strongly bias most of the compounds in Table 2 towards the particle phase. For instance, the most abundant ion, pinic acid, has a vapour pressure $\sim 2 \mu \mathrm{g} \mathrm{m}^{-3}$ at $294 \mathrm{~K}$ (Bilde and Pandis, 2001), so $>99 \%$ would be expected to reside in the particle phase based on an absorptive partitioning argument (Pankow, 1994). This might explain the lack of detected species in the present SOA system. However, a number of studies have detected gas-phase species using an electrospray source - e.g. Horan et al. (2012), Wu et al. (2000) and Zhao et al. (2017a). The ion source design and operating parameters appear important in determining the ionisation efficiency and mechanism (uptake into droplets or gas-phase chemical ionisation). Future work to simultaneously detect semi-volatile species in both phases, and understand the relative efficiencies of gas- and particle-phase ionisation, is therefore merited. 


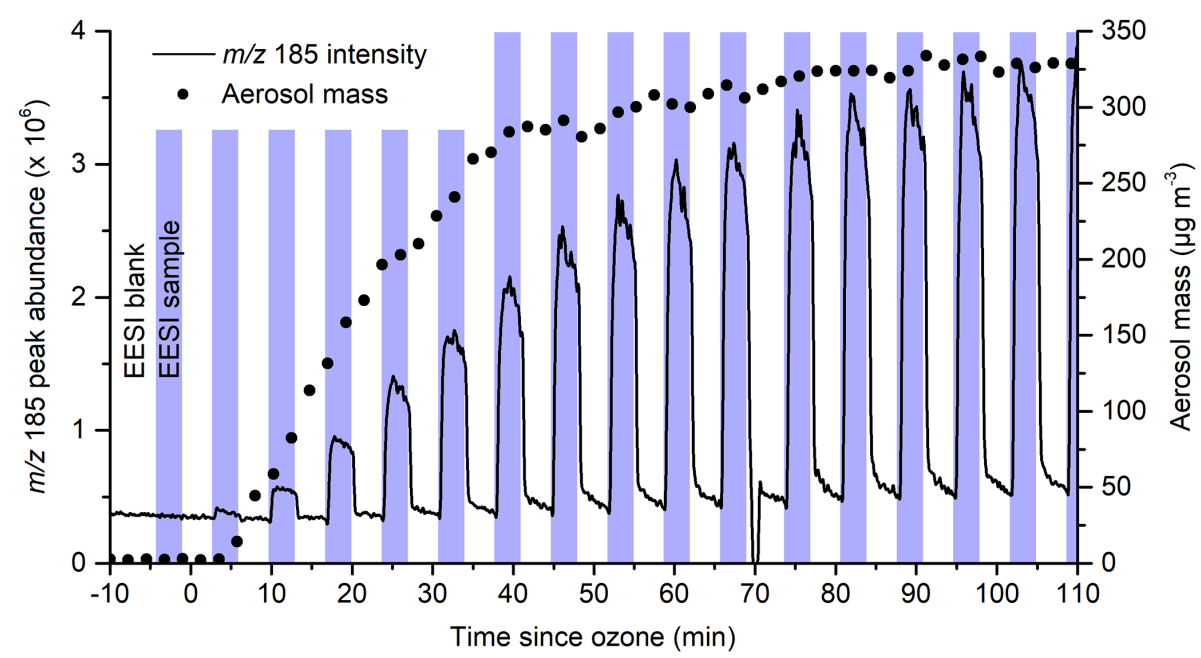

Figure 6. Left $y$ axis: peak abundance of $m / z$ 185.0819, corresponding to pinic acid, after the start of an $\alpha$-pinene ozonolysis experiment. Right $y$ axis: mass concentration of aerosol in the chamber. The measurements were made using the new EESI-MS batch sampling system (Fig. 1). Blue bands correspond to sampling of chamber air from the reservoir volume (3.5 min) while the blanks in between correspond to clean air flushing (3.5 min). The MS discontinuity around 70 min corresponds to refilling of the primary EESI solvent syringe.

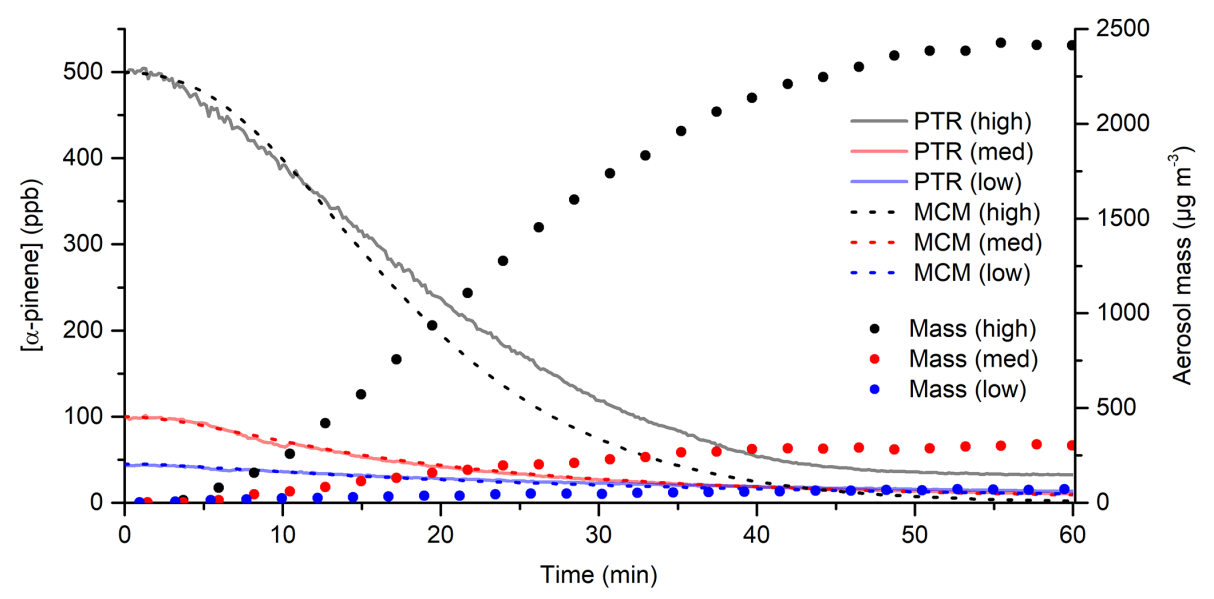

Figure 7. $\alpha$-Pinene loss and SOA production during chamber experiments with varying $[\alpha \text {-pinene }]_{0}$. Solid lines: measured $[\alpha$-pinene $]$ from PTR-MS; dashed lines: MCM simulated [ $\alpha$-pinene]; points: measured aerosol mass from SMPS.

\subsubsection{Comparing measured and modelled time dependence of individual species}

An important application of simulation chamber experiments is to better constrain and validate atmospheric reaction mechanisms, particularly for complex VOC chemistry. We compare here individual species measured during the chamber experiments using PTR-MS and EESI-MS to predictions from the AtChem chamber box model using the near-explicit $\alpha$-pinene oxidation scheme from the MCM (referred to as "MCM simulations" from this point). We focus on the first hour of each experiment to assess how the techniques capture the time evolution of composition.

We first benchmark the simulations to measurements of [ $\alpha$-pinene] using PTR-MS, an established technique. Fig- ure 7 shows the simulated and measured $\alpha$-pinene concentrations in the chamber for experiments with $[\alpha \text {-pinene }]_{0}=45$, 100 and $500 \mathrm{ppb}$ (referred to as low, medium and high respectively) and $\left[\mathrm{O}_{3}\right]_{\max } /[\alpha \text {-pinene }]_{0}=3$. Also shown on the secondary $y$ axis are the corresponding measured SOA concentrations.

The "sigmoidal" shape of the $\alpha$-pinene loss is a consequence of ozone being introduced over a finite period of up to $30 \mathrm{~min}$ at the start of the experiment, as discussed in Sect. 2.2. The MCM generally performs well in simulating the observed $\alpha$-pinene concentration, especially for the lowand medium-concentration conditions when the ozone introduction period was only a few minutes. An expanded view of the low and medium experiments is provided in Fig. S5. The largest discrepancy is for the high-concentration experi- 
ment, where the simulated loss is more rapid than measured. We attribute this to the longer ozone introduction time in this experiment $(\sim 30 \mathrm{~min})$, which will lead to a more uncertain chamber mixing state at the start of the experiment.

We now demonstrate a comparison of aerosol-phase EESI(-)-MS peak abundances to the MCM for individual species across the low-, medium- and high-concentration conditions from Table 1. Figure 8 shows time series for $m / z$ 183.1027, $m / z 185.0819$ and $m / z$ 199.0976, assigned as pinonic acid, pinic acid and $\mathrm{OH}$-pinonic acid respectively (Table 2). The secondary $y$ axes show simulated concentrations of these species from the MCM under the corresponding conditions.

The overall agreement between MS abundances and MCM simulations is very encouraging. The measurements and model compare well in two respects: the time dependence of product formation, and the relative concentrations of a given product in the low, medium and high conditions. Note that the MS abundances of the three compounds cannot be directly compared without calibration due to the species' different IEs.

The product time series reflect the rate of consumption of $\alpha$-pinene in the chamber. As for $\alpha$-pinene, a pronounced "sigmoidal" profile is observed and simulated for the highconcentration conditions, and the slightly overpredicted $\alpha$ pinene loss rate may explain the more rapid growth of pinonic acid and pinic acid in the model than measured. $\mathrm{OH}-$ pinonic acid is a close fit to the model under the range of conditions tested.

The individual product yields after $1 \mathrm{~h}$ (when the $\alpha$ pinene precursor has been almost completely consumed and timing uncertainties are less important) compare well between measurement and model and scale approximately with $[\alpha \text {-pinene }]_{0}$. Typically, these relative measured and modelled yields are self-consistent for a given product to within $\sim 25 \%$, except for pinonic acid in the low-concentration experiment. The data for low- and medium-concentration time series are shown in more detail in Fig. S6.

Although pinonic acid, pinic acid and $\mathrm{OH}-$ pinonic acid are reported as major particle-phase oxidation products in a range of studies (Table 2), the discussion above assumes that the gas-phase concentrations from the MCM are a good proxy for particle-phase concentrations assessed by EESIMS. Particle-phase reactions are unlikely to be a large source or sink of these major products, although they may be important for a range of high-molecular-weight species (Camredon et al., 2010). The equilibrium partitioning of products between the gas and particle phases will favour the particle phase for pinic acid and $\mathrm{OH}$-pinonic acid because their saturation concentrations $\left(<10 \mu \mathrm{g} \mathrm{m}^{-3}\right.$; Müller et al., 2012; Yatavelli et al., 2014) are substantially lower than aerosol mass loadings (100-2400 $\mathrm{g} \mathrm{m}^{-3}$ ) in our experiments.

Pinonic acid is thought to have a significantly higher saturation concentration (in the range $10^{2}-10^{3} \mu \mathrm{g} \mathrm{m}^{-3}$ depending on the temperature and estimation method used; Müller
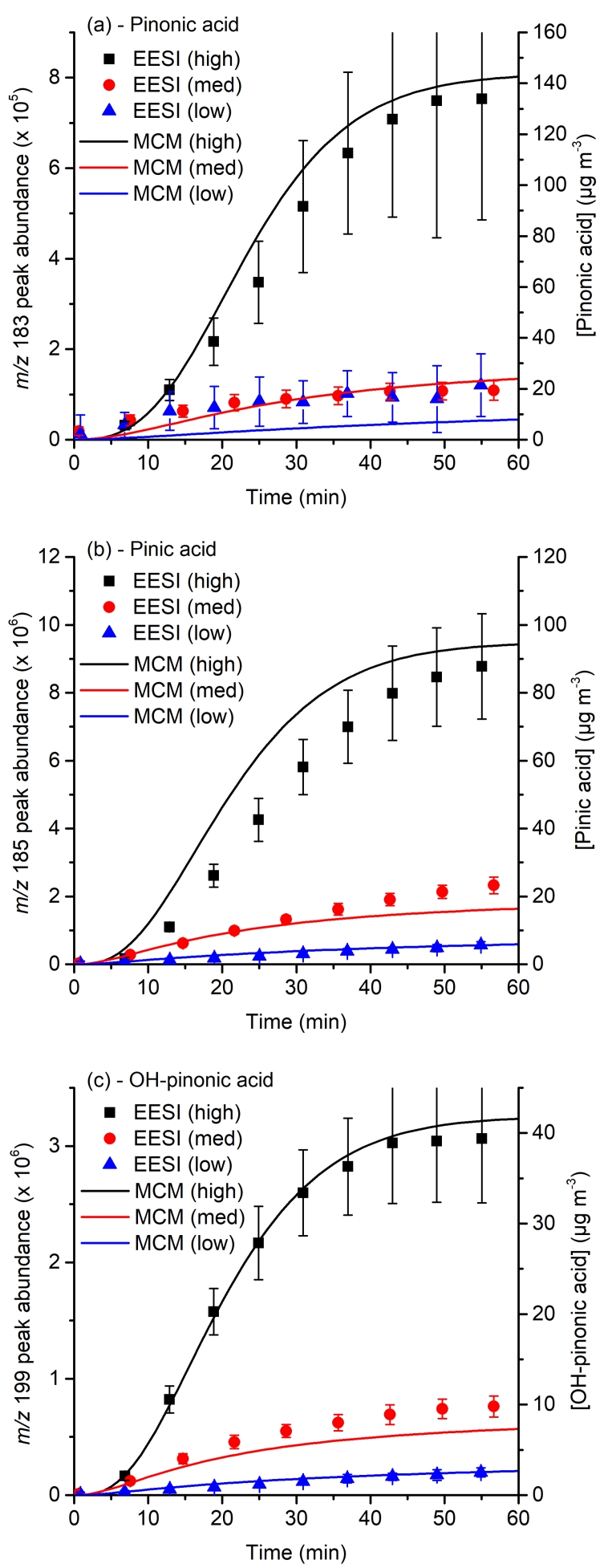

Figure 8. Comparison between EESI-MS peak abundances (left $y$ axis) and MCM simulated concentrations (right $y$ axis) for (a) pinonic acid, (b) pinic acid and (c) $\mathrm{OH}$-pinonic acid during chamber experiments with different $[\alpha \text {-pinene }]_{0}$. MS abundances are absolute, following averaging and blank subtraction. The measurements and model agree closely both in terms of the time dependence of product formation and the relative yields under different reaction conditions. 
et al., 2012; Yatavelli et al., 2014). Hence, it is expected to reside across both phases in our experiments. However, a few observations suggest that the aerosol phase is still favoured here. Gas-phase concentrations estimated by PTRMS are a small fraction of the corresponding MCM predictions in Fig. 8a. The measured EESI-MS peak abundances also track the predicted MCM concentrations relatively well over time, even as the aerosol mass loading in the chamber is increasing substantially. Zhang et al. (2015) found that aerosol-phase concentrations of pinonic acid increased substantially at $50 \% \mathrm{RH}$ (similar to $60 \%$ here) compared to dry conditions, and a recent field study concluded that measured pinonic acid concentrations in the aerosol exceeded absorptive partitioning predictions by a factor of $\sim 20$ (Yatavelli et al., 2014). Given the relatively high predicted Henry's law coefficient of pinonic acid $\left(\sim 2 \times 10^{7} \mathrm{M} \mathrm{atm}^{-1}\right.$; Lignell et al., 2013), it may be that the presence of aerosol liquid water enhances uptake into the aerosol phase. As for all products in our study, structural isomers of the assignments in Table 2 may also be present as isobaric ions in our mass spectra.

Despite the potential limitations of this comparison, Fig. 8 provides further evidence that EESI-MS can be used for relative quantification of individual species in organic aerosols. Moreover, it extends this applicability to scenarios where the particles contain a complex mixture of components, and where the particle composition, size and total mass are evolving. Specifically, we have demonstrated here that the influence of the bulk aerosol "matrix" on EESI ionisation appears to be negligible up to SOA loadings of $\sim 2400 \mu \mathrm{g} \mathrm{m}^{-3}$ and that the EESI mechanism can tolerate small quantities of inorganic material. The time evolution is also well captured for much lower analyte concentrations of a few $\mu \mathrm{g} \mathrm{m}^{-3}$ (Fig. S6c). This is a significant advantage compared to conventional direct infusion ESI-MS, where ion abundances are typically only used as a qualitative indicator, if at all, due to strong matrix effects.

Figure 9 shows the measured EESI(-)-MS signal plotted against the corresponding simulated concentration at that time for OH-pinonic acid, which shows the best correlation in time between measurement and model of the three compounds discussed in Fig. 8. This relationship is linear over orders of magnitude in concentration, and regions where the concentrations coincide (e.g. the initial point of the "high" experiment with later points in the "low" and "medium" experiments) overlap well. Figure S7 shows an illustrative plot for all three species from Fig. 8, using only the concentrations around $1 \mathrm{~h}$ to minimise timing uncertainties discussed above.

This representation is analogous to the plots for tartaric acid shown in Fig. 2, except that the MS signal is compared to the model rather than a known analyte concentration. In principle, a direct calibration curve such as Fig. 2 would allow MS abundances to be converted to absolute concentrations for any species where authentic standards are available. In practice, however, the number of species present

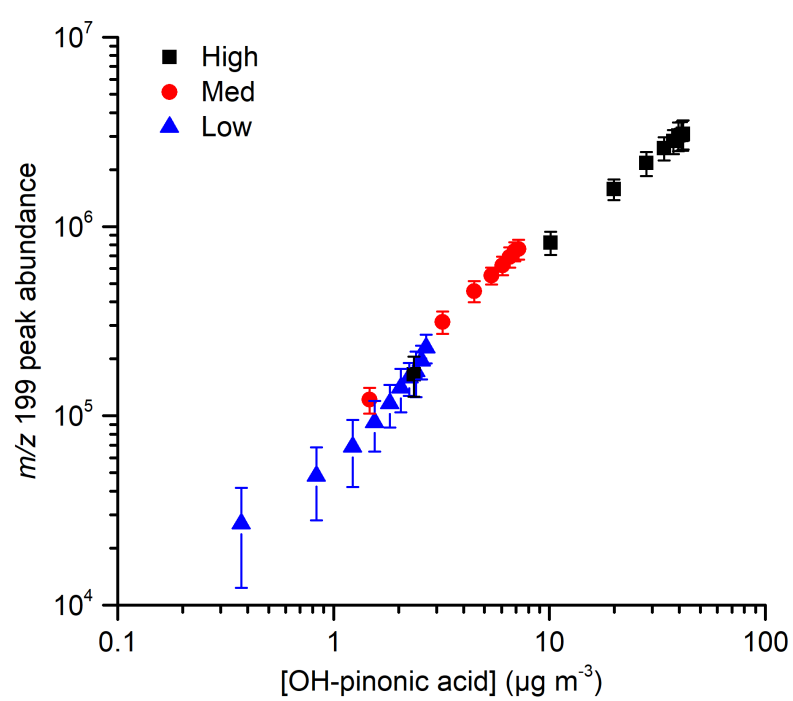

Figure 9. Correlation between MS peak abundance and MCM mass across three different experiments for $\mathrm{OH}$-pinonic acid.

in aerosols, and the general unavailability of suitable standards, makes this approach impractical for routine quantification. Comparison to modelled concentrations in this way may therefore provide an approximate indicator of IE for a range of different species in aerosols. However, as discussed above, care is required in interpreting aerosol-phase concentration changes for the many species where in-particle reaction or gas-particle partitioning may be significant. A coupled model of aerosol- and gas-phase chemistry (Gallimore et al., 2017a; Shiraiwa et al., 2010) would therefore be a desirable tool to use alongside future chamber experiments.

\section{Conclusions}

Online measurements of particle- and gas-phase chemistry in the new Cambridge Atmospheric Simulation Chamber (CASC) have been achieved simultaneously using complementary "soft" ionisation mass spectrometry techniques: EESI and PTR. The results for EESI-MS are encouraging and prompt continuing use and further development of the technique in future. Its principal advantages over conventional electrospray techniques are (1) the sample and blank measurements are obtained online, providing highly time resolved information with fewer potential artefacts, and (2) that ion abundance can be used as a relative measure of concentration due to the lack of matrix interference, and in principle converted to an absolute concentration via calibration.

The lack of matrix interference in EESI-MS compared to direct ESI-MS has been noted in other applications. The mechanistic differences are not fully understood, but a likely rationale is that the primary electrospray conditions are constant during EESI, but vary substantially depending on the dissolved analytes in direct ESI. Our work (here and in previ- 
ous studies) shows a correlation between MS signal and total analyte mass which does not appear to saturate at the upper end of the concentration range tested $\left(\sim 2400 \mu \mathrm{g} \mathrm{m}^{-3}\right)$. This implies that there is an excess of primary charged droplets available to extract and ionise the aerosol components, and hence that the MS abundance of each analyte depends on its relative ionisation efficiency, which has been modelled as a function of a species' ionisation in solution and ability to delocalise charge (Kruve et al., 2014). Our limited tests with this EESI-MS configuration show that the signal arising is a result of droplet-particle collisions, with negligible contribution from gas-phase analytes. Further insight into the EESI mechanism may be obtained by assessing when and how MS saturation behaviour occurs at higher mass loadings.

Improving EESI-MS sensitivity would be an advantage in future atmospheric chemistry applications. The downside of our Orbitrap mass spectrometer is that the instrument's ion collection and transmission properties are less efficient relative to other instruments. Coupling the EESI ion source to an alternative mass analyser is an area of active investigation. Pre-concentrating the airborne particles using a virtual impactor system similar to Vogel et al. (2013) may also provide an order-of-magnitude boost to sensitivity.

Although out of the scope of the current study, our molecular composition measurements from the chamber may be amenable to detailed process modelling. A model which includes descriptions of gas-particle partitioning, alongside reactions in both phases, may be better able to capture the dynamic evolution of particle-phase components and probe multiphase processing and extended aging of the initial products.

Data availability. Data presented in this study can be obtained by contacting the corresponding authors.

\section{Information about the Supplement}

The Supplement contains details related to operation of the atmospheric chamber and EESI sampling system, further details about MCM modelling, full EESI-MS and PTR-MS spectra, and additional figures comparing the online MS measurements to MCM simulations.

\section{The Supplement related to this article is available online at https://doi.org/10.5194/acp-17-14485-2017- supplement.}

Competing interests. The authors declare that they have no conflict of interest.

Acknowledgements. This work was funded by the European Research Council (grant 279405), the UK Natural Environment
Research Council (grant NE/H52449X/1) and the Velux Foundations (project number 593).

Edited by: Sergey A. Nizkorodov

Reviewed by: two anonymous referees

\section{References}

Aiken, A. C., Decarlo, P. F., Kroll, J. H., Worsnop, D. R., Huffman, J. A., Docherty, K. S., Ulbrich, I. M., Mohr, C., Kimmel, J. R., Sueper, D., Sun, Y., Zhang, Q., Trimborn, A., Northway, M. J., Ziemann, P. J., Canagaratna, M. R., Onasch, T. B., Alfarra, M. R., Prevot, A. S. H., Dommen, J., Duplissy, J., Metzger, A., Baltensperger, U., and Jimenez, J. L.: O / C and OM / OC Ratios of Primary, Secondary, and Ambient Organic Aerosols with HighResolution Time-of-Flight Aerosol Mass Spectrometry, Environ. Sci. Technol., 42, 4478-4485, 2008.

Bateman, A. P., Nizkorodov, S. A., Laskin, J., and Laskin, A.: Time-resolved molecular characterization of limonene/ozone aerosol using high-resolution electrospray ionization mass spectrometry, Phys. Chem. Chem. Phys., 11, 7931-7942, https://doi.org/10.1039/b916865f, 2009.

Bilde, M. and Pandis, S. N.: Evaporation Rates and Vapor Pressures of Individual Aerosol Species Formed in the Atmospheric Oxidation of alpha- and beta-Pinene, Environ. Sci. Technol., 35, 3344-3349, 2001.

Blake, R. S., Monks, P. S., and Ellis, A. M.: Protontransfer reaction mass spectrometry, Chem. Rev., 109, 861-96, https://doi.org/10.1021/cr800364q, 2009.

Boucher, O., Randall, D., Artaxo, P., Bretherton, C., Feingold, G., Forster, P., Kerminen, V.-M., Kondo, Y., Liao, H., Lohmann, U., Rasch, P., Satheesh, S. K., Sherwood, S., Stevens, B., and Zhang, X. Y.: Clouds and Aerosols, in: Climate Change 2013: The Physical Science Basis, Contribution of Working Group I to the Fifth Assessment Report of the Intergovernmental Panel on Climate Change, edited by: Stocker, T. F., Qin, D., Plattner, G.-K., Tignor, M., Allen, S. K., Boschung, J., Nauels, A., Xia, Y., Bex, V., and Midgley, P. M., 2013.

Brüggemann, M., Karu, E., Stelzer, T., and Hoffmann, T.: Real-time analysis of ambient organic aerosols using aerosol flowing atmospheric-pressure afterglow mass spectrometry (AeroFAPA-MS), Environ. Sci. Technol., 49, 5571-5578, https://doi.org/10.1021/es506186c, 2015.

Camredon, M., Hamilton, J. F., Alam, M. S., Wyche, K. P., Carr, T., White, I. R., Monks, P. S., Rickard, A. R., and Bloss, W. J.: Distribution of gaseous and particulate organic composition during dark alpha-pinene ozonolysis, Atmos. Chem. Phys., 10, 2893 2917, https://doi.org/10.5194/acpd-9-27837-2009, 2010.

Chen, H., Venter, A., and Cooks, R. G.: Extractive electrospray ionization for direct analysis of undiluted urine, milk and other complex mixtures without sample preparation, Chem. Commun., 2042-2044, https://doi.org/10.1039/b602614a, 2006.

Claeys, M., Iinuma, Y., Szmigielski, R., Surratt, J. D., Blockhuys, F., van Alsenoy, C., Bogen, O., Sierau, B., Gomez-Gonzalez, Y., Vermeylen, R., van der Veken, P., Shahgholi, M., Chan, A. W. H., Herrmann, H., Seinfeld, J. H., and Maenhaut, W.: Terpenylic Acid and Related Compounds from the Oxidation of alpha- 
Pinene?: Implications for New Particle Formation and Growth above Forests, Environ. Sci. Technol., 43, 6976-6982, 2009.

Clark, C. H., Nakao, S., Asa-Awuku, A., Sato, K., and Cocker, D. R.: Real-Time Study of Particle-Phase Products from $\alpha$-Pinene Ozonolysis and Isoprene Photooxidation Using Particle into Liquid Sampling Directly Coupled to a Time-of-Flight Mass Spectrometer (PILS-ToF), Aerosol Sci. Technol., 47, 1374-1382, https://doi.org/10.1080/02786826.2013.844333, 2014.

Cocker, D. R., Flagan, R. C., and Seinfeld, J. H.: Stateof-the-art chamber facility for studying atmospheric aerosol chemistry, Environ. Sci. Technol., 35, 2594-2601, https://doi.org/10.1021/es0019169, 2001.

DeCarlo, P. F., Kimmel, J. R., Trimborn, A., Northway, M. J., Jayne, J. T., Aiken, A. C., Gonin, M., Fuhrer, K., Horvath, T., Docherty, K. S., Worsnop, D. R., and Jimenez, J. R.: Field-Deployable, High-Resolution, Time-of-Flight, Aerosol Mass Spectrometer, 78, 8281-8289, 2006.

Devenport, N. A., Blenkhorn, D. J., Weston, D. J., Reynolds, J. C., and Creaser, C. S.: Direct Determination of Urinary Creatinine by Reactive-Thermal Desorption-Extractive ElectrosprayIon Mobility-Tandem Mass Spectrometry, Anal. Chem., 86, 357361, 2014.

Doezema, L. A., Longin, T., Cody, W., Perraud, V., Dawson, M. L., Ezell, M. J., Greaves, J., Johnson, K. R., and Finlayson-Pitts, B. J.: Analysis of secondary organic aerosols in air using extractive electrospray ionization mass spectrometry (EESI-MS), RSC Adv., 2, 2930-2938, https://doi.org/10.1039/c2ra00961g, 2012.

Dominici, F., Peng, R. D., Bell, M. L., Pham, L., McDermott, A., Zeger, S. L., and Samet, J. M.: Fine particulate air pollution and hospital admission for cardiovascular and respiratory diseases, J. Am. Med. Assoc., 295, 1127-1134, https://doi.org/10.1001/jama.295.10.1127, 2006.

Edney, E. O., Kleindienst, T. E., Jaoui, M., Lewandowski, M., Offenberg, J. H., Wang, W., and Claeys, M.: Formation of 2-methyl tetrols and 2-methylglyceric acid in secondary organic aerosol from laboratory irradiated isoprene $/ \mathrm{NO}_{x} / \mathrm{SO}_{2} /$ air mixtures and their detection in ambient $\mathrm{PM}_{2.5}$ samples collected in the eastern United States, Atmos. Environ., 39, 5281-5289, https://doi.org/10.1016/j.atmosenv.2005.05.031, 2005.

Gallimore, P. J. and Kalberer, M.: Characterizing an extractive electrospray ionization (EESI) source for the online mass spectrometry analysis of organic aerosols, Environ. Sci. Technol., 47, 7324-31, https://doi.org/10.1021/es305199h, 2013.

Gallimore, P. J., Griffiths, P. T., Pope, F. D., Reid, J. P., and Kalberer, M.: Comprehensive modeling study of ozonolysis of oleic acid aerosol based on real-time, online measurements of aerosol composition, J. Geophys. Res.-Atmos., 122, 4364-4377, https://doi.org/10.1002/2016JD026221, 2017a.

Gallimore, P. J., Mahon, B. M., Wragg, F. P. H., Fuller, S. J., Giorio, C., Kourtchev, I., and Kalberer, M.: Multiphase composition changes and reactive oxygen species formation during limonene oxidation in the new Cambridge Atmospheric Simulation Chamber (CASC), Atmos. Chem. Phys., 17, 9853-9868, https://doi.org/10.5194/acp-2017-186, 2017b.

Goldstein, A. H. and Galbally, I. E.: Known and Unexplored Organic Constituents in the Earth's Atmosphere, Environ. Sci. Technol., 41, 1515-1521, 2007.

Guenther, A. B., Jiang, X., Heald, C. L., Sakulyanontvittaya, T., Duhl, T., Emmons, L. K., and Wang, X.: The Model of
Emissions of Gases and Aerosols from Nature version 2.1 (MEGAN2.1): an extended and updated framework for modeling biogenic emissions, Geosci. Model Dev., 5, 1471-1492, https://doi.org/10.5194/gmd-5-1471-2012, 2012.

Hall IV, W. A. and Johnston, M. V.: Oligomer formation pathways in secondary organic aerosol from MS and MS/MS measurements with high mass accuracy and resolving power, J. Am. Soc. Mass Spectr., 23, 1097-1108, https://doi.org/10.1007/s13361012-0362-6, 2012.

Hallquist, M., Wenger, J. C., Baltensperger, U., Rudich, Y., Simpson, D., Claeys, M., Dommen, J., Donahue, N. M., George, C., Goldstein, A. H., Hamilton, J. F., Herrmann, H., Hoffmann, T., Iinuma, Y., Jang, M., Jenkin, M. E., Jimenez, J. L., Kiendler-Scharr, A., Maenhaut, W., McFiggans, G., Mentel, Th. F., Monod, A., Prévôt, A. S. H., Seinfeld, J. H., Surratt, J. D., Szmigielski, R., and Wildt, J.: The formation, properties and impact of secondary organic aerosol: current and emerging issues, Atmos. Chem. Phys., 9, 5155-5236, https://doi.org/10.5194/acp9-5155-2009, 2009.

Hoffmann, T., Huang, R.-J., and Kalberer, M.: Atmospheric Analytical Chemistry, Anal. Chem., 83, 4649-64, https://doi.org/10.1021/ac2010718, 2011.

Horan, A. J., Gao, Y., Hall, W. A., and Johnston, M. V: Online Characterization of Particles and Gases with an Ambient Electrospray Ionization Source, Anal. Chem., 84, 9253-9258, 2012.

Husar, R. B., Holloway, J. M., and Patterson, D. E.: Spatial and temporal pattern of eastern US haziness: A summary, Atmos. Environ., 15, 1919-28, https://doi.org/10.1016/0004-6981(81)902262, 1981.

Jayne, J. T., Leard, D. C., Zhang, X., Davidovits, P., Smith, K. A. , Kolb, C. E., and Worsnop, D. R.: Development of an Aerosol Mass Spectrometer for Size and Composition Analysis of Submicron Particles, Aerosol Sci. Technol., 33, 49-70, 2000.

Jenkin, M. E.: Modelling the formation and composition of secondary organic aerosol from $\alpha$ - and $\beta$-pinene ozonolysis using MCM v3, Atmos. Chem. Phys., 4, 1741-1757, https://doi.org/10.5194/acp-4-1741-2004, 2004.

Jenkin, M. E., Saunders, S. M., and Pilling, M. J.: The Tropospheric Degradation of Volatile Organic Compounds: A Protocol for Mechanism Development, Atmos. Environ., 31, 81-104, 1997.

Jimenez, J. L., Canagaratna, M. R., Donahue, N. M., Prevot, A. S. H., Zhang, Q., Kroll, J. H., DeCarlo, P. F., Allan, J. D., Coe, H., Ng, N. L., Aiken, A. C., Docherty, K. S., Ulbrich, I. M., Grieshop, a P., Robinson, A. L., Duplissy, J., Smith, J. D., Wilson, K. R., Lanz, V. A., Hueglin, C., Sun, Y. L., Tian, J., Laaksonen, A., Raatikainen, T., Rautiainen, J., Vaattovaara, P., Ehn, M., Kulmala, M., Tomlinson, J. M., Collins, D. R., Cubison, M. J., Dunlea, E. J., Huffman, J. A., Onasch, T. B., Alfarra, M. R., Williams, P. I., Bower, K., Kondo, Y., Schneider, J., Drewnick, F., Borrmann, S., Weimer, S., Demerjian, K., Salcedo, D., Cottrell, L., Griffin, R., Takami, A., Miyoshi, T., Hatakeyama, S., Shimono, A., Sun, J. Y., Zhang, Y. M., Dzepina, K., Kimmel, J. R., Sueper, D., Jayne, J. T., Herndon, S. C., Trimborn, A. M., Williams, L. R., Wood, E. C., Middlebrook, A. M., Kolb, C. E., Baltensperger, U., and Worsnop, D. R.: Evolution of organic aerosols in the atmosphere, Science, 326, 1525-1529, https://doi.org/10.1126/science.1180353, 2009. 
Kampf, C. J., Jakob, R., and Hoffmann, T.: Identification and characterization of aging products in the glyoxal/ammonium sulfate system - Implications for light-absorbing material in atmospheric aerosols, Atmos. Chem. Phys., 12, 6323-6333, https://doi.org/10.5194/acp-12-6323-2012, 2012.

Kourtchev, I., Fuller, S. J., Giorio, C., Healy, R. M., Wilson, E., O'Connor, I., Wenger, J. C., McLeod, M., Aalto, J., Ruuskanen, T. M., Maenhaut, W., Jones, R., Venables, D. S., Sodeau, J. R., Kulmala, M., and Kalberer, M.: Molecular composition of biogenic secondary organic aerosols using ultrahigh-resolution mass spectrometry: comparing laboratory and field studies, Atmos. Chem. Phys., 14, 2155-2167, https://doi.org/10.5194/acp14-2155-2014, 2014.

Kristensen, K., Enggrob, K. L., King, S. M., Worton, D. R., Platt, S. M., Mortensen, R., Rosenoern, T., Surratt, J. D., Bilde, M., Goldstein, A. H., and Glasius, M.: Formation and occurrence of dimer esters of pinene oxidation products in atmospheric aerosols, Atmos. Chem. Phys., 13, 3763-3776, https://doi.org/10.5194/acp13-3763-2013, 2013.

Kroll, J. H. and Seinfeld, J. H.: Chemistry of secondary organic aerosol: Formation and evolution of low-volatility organics in the atmosphere, Atmos. Environ., 42, 3593-3624, https://doi.org/10.1016/j.atmosenv.2008.01.003, 2008.

Kroll, J. H., Donahue, N. M., Jimenez, J. L., Kessler, S. H., Canagaratna, M. R., Wilson, K. R., Altieri, K. E., Mazzoleni, L. R., Wozniak, A. S., Bluhm, H., Mysak, E. R., Smith, J. D., Kolb, C. E., and Worsnop, D. R.: Carbon oxidation state as a metric for describing the chemistry of atmospheric organic aerosol, Nat. Chem., 3, 133-139, https://doi.org/10.1038/nchem.948, 2011.

Kruve, A., Kaupmees, K., Liigand, J., and Leito, I.: Negative Electrospray Ionization via Deprotonation: Predicting the Ionization Efficiency, 86, 4822-4830, 2014.

Law, W. S., Chen, H. W., Balabin, R., Berchtold, C., Meier, L., and Zenobi, R.: Rapid fingerprinting and classification of extra virgin olive oil by microjet sampling and extractive electrospray ionization mass spectrometry, Analyst, 135, 773-8, https://doi.org/10.1039/b924156f, 2010.

Lee, A., Goldstein, A. H., Keywood, M. D., Gao, S., Varutbangkul, V., Bahreini, R., Ng, N. L., Flagan, R. C., and Seinfeld, J. H.: Gas-phase products and secondary aerosol yields from the ozonolysis of ten different terpenes, J. Geophys. Res., 111, D07302, https://doi.org/10.1029/2005JD006437, 2006.

Lignell, H., Epstein, S. A., Marvin, M. R., Shemesh, D., Gerber, B., and Nizkorodov, S.: Experimental and Theoretical Study of Aqueous cis-Pinonic Acid Photolysis, J. Phys. Chem. A, 117, 12930-12945, 2013.

Lindinger, W., Hansel, A., and Jordan, A.: Proton-transfer-reaction mass spectrometry (PTR-MS): On-line monitoring of volatile organic compounds at pptv levels, Chem. Soc. Rev., 27, 347-354, 1998.

McCullough, B. J., Bristow, T., O'Connor, G., and Hopley, C.: On-line reaction monitoring by extractive electrospray ionisation, Rapid Commun. Mass Spectr., 25, 1445-1451, https://doi.org/10.1002/rcm.5016, 2011.

Müller, L., Reinnig, M.-C., Naumann, K. H., Saathoff, H., Mentel, T. F., Donahue, N. M., and Hoffmann, T.: Formation of 3methyl-1,2,3-butanetricarboxylic acid via gas phase oxidation of pinonic acid - a mass spectrometric study of SOA aging, At- mos. Chem. Phys., 12, 1483-1496, https://doi.org/10.5194/acp12-1483-2012, 2012.

Nah, T., Chan, M., Leone, S. R., and Wilson, K. R.: Real Time in Situ Chemical Characterization of Submicrometer Organic Particles Using Direct Analysis in Real Time-Mass Spectrometry, Anal. Chem., 85, 2087-95, https://doi.org/10.1021/ac302560c, 2013.

Noziere, B., Kalberer, M., Claeys, M., Allan, J., Anna, B. D., Decesari, S., Finessi, E., Glasius, M., Grgic, I., Hamilton, J. F., Ho, T., Iinuma, Y., Jaoui, M., Kahnt, A., Kampf, C. J., Kourtchev, I., Maenhaut, W., Marsden, N., Saarikoski, S., Schnelle-kreis, J., Surratt, J. D., Szidat, S., Szmigielski, R., and Wisthaler, A.: The Molecular Identification of Organic Compounds in the Atmosphere: State of the Art and Challenges, Chem. Rev., 115, 39193983, https://doi.org/10.1021/cr5003485, 2015.

Pankow, J. F.: An absorption model of the gas/aerosol partitioning involved in the formation of secondary organic aerosol, Atmos. Environ., 28, 189-193, 1994.

Paulsen, D., Dommen, J., Kalberer, M., Prévôt, A. S. H., Richter, R., Sax, M., Steinbacher, M., Weingartner, E., and Baltensperger, U.: Secondary organic aerosol formation by irradiation of 1,3,5trimethylbenzene- $\mathrm{NO}_{x}-\mathrm{H}_{2} \mathrm{O}$ in a new reaction chamber for atmospheric chemistry and physics, Environ. Sci. Technol., 39, 2668-2678, https://doi.org/10.1021/es0489137, 2005.

Pereira, K. L., Hamilton, J. F., Rickard, A. R., Bloss, W. J., Alam, M. S., Camredon, M., Muñoz, A., Vázquez, M., Borrás, E., and Ródenas, M.: Secondary organic aerosol formation and composition from the photo-oxidation of methyl chavicol (estragole), Atmos. Chem. Phys., 14, 5349-5368, https://doi.org/10.5194/acp14-5349-2014, 2014.

Reinhardt, A., Emmenegger, C., Gerrits, B., Panse, C., Dommen, J., Baltensperger, U., Zenobi, R., and Kalberer, M.: Ultrahigh Mass Resolution and Accurate Mass Measurements as a Tool To Characterize Oligomers in Secondary Organic Aerosols, Anal. Chem., 79, 4074-4082, https://doi.org/10.1029/2003GL018962, 2007.

Saunders, S. M., Jenkin, M. E., Derwent, R. G., and Pilling, M. J.: Protocol for the development of the Master Chemical Mechanism, MCM v3 (Part A): tropospheric degradation of nonaromatic volatile organic compounds, Atmos. Chem. Phys., 3, 161-180, https://doi.org/10.5194/acp-3-161-2003, 2003.

Shiraiwa, M., Pfrang, C., and Pöschl, U.: Kinetic multi-layer model of aerosol surface and bulk chemistry (KM-SUB): the influence of interfacial transport and bulk diffusion on the oxidation of oleic acid, Atmos. Chem. Phys, 10, 281-326, https://doi.org/10.5194/acp-10-3673-2010, 2010.

Smith, D. and Španěl, P.: Selected Ion Flow Tube Mass Spectrometry (SIFT-MS) for on-line trace gas analysis, Mass Spectrom. Rev., 24, 661-700, https://doi.org/10.1002/mas.20033, 2005.

Turpin, B. J., Saxena, P., and Andrews, E.: Measuring and simulating particulate organics in the atmosphere: problems and prospects, Atmos. Environ., 34, 2983-3013, https://doi.org/10.1016/S1352-2310(99)00501-4, 2000.

Vogel, A. L., Äijälä, M., Corrigan, A. L., Junninen, H., Ehn, M., Petäjä, T., Worsnop, D. R., Kulmala, M., Russell, L. M., Williams, J., and Hoffmann, T.: In situ submicron organic aerosol characterization at a boreal forest research station during HUMPPA-COPEC 2010 using soft and hard ionization mass spectrometry, Atmos. Chem. Phys., 13, 10933-10950, https://doi.org/10.5194/acp-13-10933-2013, 2013. 
Wisthaler, A., Jensen, N. R., Winterhalter, R., Lindinger, W., and Hjorth, J.: Measurements of acetone and other gas phase product yields from the $\mathrm{OH}$-initiated oxidation of terpenes by protontransfer-reaction mass spectrometry (PTR-MS), Atmos. Environ., 35, 6181-6191, 2001.

Wu, C., Siems, W. F., and Hill Jr., H. H.: Secondary Electrospray Ionization Ion Mobility Spectrometry/Mass Spectrometry of Illicit Drugs, Anal. Chem., 72, 396-403, 2000.

Yatavelli, R. L. N., Stark, H., Thompson, S. L., Kimmel, J. R., Cubison, M. J., Day, D. A., Campuzano-Jost, P., Palm, B. B., Hodzic, A., Thornton, J. A., Jayne, J. T., Worsnop, D. R., and Jimenez, J. L.: Semicontinuous measurements of gas-particle partitioning of organic acids in a ponderosa pine forest using a MOVI-HRToF-CIMS, Atmos. Chem. Phys., 14, 1527-1546, https://doi.org/10.5194/acp-14-1527-2014, 2014.

Zhang, X., McVay, R. C., Huang, D. D., Dalleska, N. F., Aumont, B., Flagan, R. C., and Seinfeld, J. H.: Formation and evolution of molecular products in $\alpha$-pinene secondary organic aerosol, P. Natl. Acad. Sci. USA, 112, 14168-14173, https://doi.org/10.1073/pnas.1517742112, 2015.

Zhao, Y., Chan, J. K., Lopez-Hilfiker, F. D., McKeown, M. A., D'Ambro, E. L., Slowik, J. G., Riffell, J. A., and Thornton, J. A.: An electrospray chemical ionization source for real-time measurement of atmospheric organic and inorganic vapors, Atmos. Meas. Tech., 10, 3609-3625, https://doi.org/10.5194/amt10-3609-2017, 2017a.
Zhao, Y., Fairhurst, M. C., Wingen, L. M., Perraud, V., Ezell, M. J., and Finlayson-Pitts, B. J.: New insights into atmospherically relevant reaction systems using direct analysis in real-time mass spectrometry (DART-MS), Atmos. Meas. Tech., 10, 1373-1386, https://doi.org/10.5194/amt-10-1373-2017, $2017 \mathrm{~b}$.

Zhu, L., Hu, Z., Gamez, G., Law, W. S., Chen, H., Yang, S., Chingin, K., Balabin, R. M., Wang, R., Zhang, T., and Zenobi, R.: Simultaneous sampling of volatile and non-volatile analytes in beer for fast fingerprinting by extractive electrospray ionization mass spectrometry, Anal. Bioanal. Chem., 398, 405-413, https://doi.org/10.1007/s00216-010-3945-8, 2010.

Zielinski, A., Kourtchev, I., Bortolini, C., Fuller, S. J., Giorio, C., Popoola, O., Bogialli, S., Tapparo, A., Jones, R. L., and Kalberer, M.: A new processing scheme for ultra-high resolution direct infusion mass spectrometry data, Atmos. Env., in review, 2017.

Ziemann, P. J. and Atkinson, R.: Kinetics, products, and mechanisms of secondary organic aerosol formation, Chem. Soc. Rev., 41, 6582-6605, https://doi.org/10.1039/c2cs35122f, 2012. 